Carnegie Mellon University

Research Showcase@ CMU

Department of Psychology

Dietrich College of Humanities and Social Sciences

$1-2001$

\title{
Psychological interventions and the immune system: A meta-analytic review and critique.
}

Gregory E. Miller

Washington University in St Louis

Sheldon Cohen

Carnegie Mellon University, scohen@cmu.edu

Follow this and additional works at: http://repository.cmu.edu/psychology

Part of the Psychology Commons

\section{Published In}

Health Psychology, 20, 1, 47-63.

This Article is brought to you for free and open access by the Dietrich College of Humanities and Social Sciences at Research Showcase @ CMU. It has been accepted for inclusion in Department of Psychology by an authorized administrator of Research Showcase @ CMU. For more information, please contact research-showcase@andrew.cmu.edu. 


\title{
Psychological Interventions and the Immune System: A Meta-Analytic Review and Critique
}

\author{
Gregory E. Miller \\ Washington University
}

\author{
Sheldon Cohen \\ Carnegie Mellon University
}

\begin{abstract}
This article reviews evidence for the hypothesis that psychological interventions can modulate the immune response in humans and presents a series of models depicting the psychobiological pathways through which this might occur. Although more than 85 trials have been conducted, meta-analyses reveal only modest evidence that interventions can reliably alter immune parameters. The most consistent evidence emerges from hypnosis and conditioning trials. Disclosure and stress management show scattered evidence of success. Relaxation demonstrates little capacity to elicit immune change. Although these data provide only modest evidence of successful immune modulation, it would be premature to conclude that the immune system is unresponsive to psychological interventions. This literature has important conceptual and methodological issues that need to be resolved before any definitive conclusions can be reached.
\end{abstract}

Key words: psychoneuroimmunology, psychological intervention, immune function, psychological stress, stress management

Interest in the hypothesis that psychological interventions can modulate the human immune response has grown dramatically in recent years. More than 85 intervention studies have appeared in peer-reviewed scientific journals to date, and the publication rate has been climbing steadily since the middle of the 1980s. Much of the enthusiasm for conducting intervention studies stems from their potential clinical implications. There is now considerable evidence documenting links between psychological stress and dysregulation of the immune response (Herbert \& Cohen, 1993). To the extent that this dysregulation contributes to excess morbidity and mortality, it is conceivable that psychological interventions could bring about positive health outcomes by altering immune system processes. Of course, psychological interventions could also influence health through a number of other pathways, but our focus here is on the immune system.

Psychological intervention research also has important theoretical implications for the field of psychoneuroimmunology. The vast majority of studies in this area use correlational research

Gregory E. Miller, Department of Psychology, Washington University; Sheldon Cohen, Department of Psychology, Carnegie Mellon University.

Preparation of this article was supported by a Postdoctoral Fellowship (MH18269) and a Senior Scientist Award (MH00721) from the National Institute of Mental Health, and by the Pittsburgh Mind-Body Center (funded by Grants HL65111 and HL65112). Edith Chen, Ian Brissette, and Joel Dopp provided comments on earlier versions of this article. We gratefully acknowledge their contributions.

Correspondence concerning this article should be addressed to Gregory Miller, Department of Psychology, Washington University, Campus Box 1125, St. Louis, Missouri 63130, or to Sheldon Cohen, Department of Psychology, Carnegie Mellon University, Pittsburgh, Pennsylvania 15213. Electronic mail may be sent to gemiller@artsci.wustl.edu or to scohen@andrew.cmu.edu. methods because of the ethical problems associated with manipulating psychological stress and clinical depression in human participants. Although correlational studies can yield important information about the links between psychosocial processes and immunity, causal inferences cannot be drawn from them because of the possibility of confounding variables and reverse-causation errors. Experimental trials of psychological interventions present investigators with a unique opportunity to circumvent these problems.

Probably the most important impetus for the growth of intervention research during recent years, however, has been excitement generated by several extremely provocative studies. One of the earliest published trials, for instance, found that people could deliberately modify their immune response when directed to do so under hypnosis (Black, 1963a). Another trial demonstrated that writing about highly traumatic events could boost the immune system's response to a routine vaccination (Petrie, Booth, Pennebaker, Davison, \& Thomas, 1995). A third study found that relaxation training could heighten specific immune responses among the elderly (Kiecolt-Glaser et al., 1985). And in perhaps the most provocative trial to date, researchers reported that a stressmanagement intervention could influence the immune responses of patients with skin cancer as well as the course of their illness (Fawzy, Cousins, et al., 1990; Fawzy, Kemeny, et al., 1990; Fawzy, et al., 1993).

These extremely provocative findings are unfortunately not representative of the literature as a whole. A number of wellconducted intervention trials have failed to document significant changes in the immune system (Coates, McKusick, Kuno, \& Stites, 1989; Locke et al., 1987; Locke et al., 1994; Lutgendorf, Antoni, Kumar, \& Schneiderman, 1994; O'Leary, Shoor, Lorig, \& Holman, 1988; Whitehouse et al., 1996). Many authors, especially in the lay press, nonetheless fail to acknowledge the mixed nature 
of evidence in this area (Bock \& Sabin, 1997; Epstein, 1989; Levine, 1991). A few well-balanced review articles on this topic have appeared in recent years (Hall \& $0^{\prime}$ Grady, 1991; Halley, 1991; Kemeny \& Miller, 1999; Kiecolt-Glaser \& Glaser, 1992; Van Rood, Bogaards, Goulmy, \& Waletzky, 1993; Zakowski; Hall, \& Baum, 1992), but their coverage has either been limited to a subset of trials or has been characterized by impressionistic summaries of findings. To provide a more complete understanding of the state of scientific affairs in this area, this article reports on a comprehensive meta-analysis of the published literature on psychological interventions and immunity.

\section{What is the Immune System?}

In this section we provide a brief introduction to the immune system and the techniques that are used to measure its status. Readers seeking a more comprehensive account of these issues are encouraged to consult any of several resources available in the field. The naïve reader will find extensive, though nontechnical, overviews of the immune system in articles by Cohen and Herbert (1996), Kiecolt-Glaser and Glaser (1995), and O'Leary (1990). Readers seeking more advanced treatments should consult texts by Benjamini, Sunshine, and Leskowitz (1996) and Rabin (1999).

The immune system is the body's chief defense against disease. Its primary function is to eradicate foreign substances that make contact with the body. These foreign substances are called pathogens and include bacteria, viruses, parasites, fungi, and other bio-organic material. The immune system clears pathogens from the body by generating responses to protein molecules that reside on their surface. These molecules are known as antigens. The immune system also eliminates bodily cells that have been transformed from their normal state through infection or malignancy and facilitates the repair of tissues that have been damaged through injury.

The cells of the immune system are called white blood cells. They are found predominantly in the bone marrow, thymus, spleen, lymph nodes, and the tissues of the skin, lung, and gastrointestinal tract. Because gaining access to these compartments requires invasive procedures, most research with humans assesses immune system function as it occurs in circulating blood. Components of the immune system are found in circulating blood because it, along with the lymphatic system, transports them between immune compartments and sites of infection and injury.

The immune system's status can be assessed with either enumerative or functional measures. Enumerative measures involve counting different immune system components. In the intervention literature, these components include white blood cell populations (granulocytes, monocytes, lymphocytes, NK cells, B-lymphocytes, T-lymphocytes, helper T-lymphocytes, and suppressor/cytotoxic T-lymphocytes), antibody populations in the blood (immunoglobulins $A, G, \& M$ ) and in saliva (secretory immunoglobulin $A$ ), and antibodies to specific pathogens (the Epstein-Barr [EBV] and herpes-simplex viruses [HSV]). Functional measures, in contrast, assess how well a specific immune system process is performed. In the intervention literature, functional assays are performed to assess how effectively natural killer cells destroy laboratory grown tumor cells, how much lymphocytes divide following stimulation with a mitogen (a substance that induces mitosis or cell division), and how effectively neutrophils can adhere to nylon fibers de- signed to simulate blood vessel walls. Other functional measures assess people's immune responses to antigens to which they are highly sensitive. This technique involves placing a small piece of antigen directly underneath the skin, a process that causes a local inflammatory response that consists of induration (a swollen round bump) and erythema (redness around the bump). The magnitude of this response can be measured immediately (an immediate-type hypersensitivity response) or 24-48 hr later (a delayed-type hypersensitivity response) depending on the antigen that is used.

Both enumerative and functional measures provide rough estimates of specific processes rather than global indications of the immune system's capacity to resist disease. Each of the measures used in this literature represents only a small facet of a complex, highly redundant system. It would therefore be inappropriate to conclude that intervention-related changes in any specific immune parameter signal a state of "immune enhancement" or altered susceptibility to immune-mediated disease. The normal functioning range for most immune measures is very broad, and psychological interventions typically do not induce changes of sufficient magnitude to move people outside of these boundaries (Cohen \& Williamson, 1991; Rabin, 1999). Even if they did, it is not clear whether the alterations would persist for a sufficient duration of time to alter risk for disease. Despite these caveats, animal studies have shown that behavioral interventions can yield immune changes of sufficient magnitude to influence morbidity and mortality (Ader \& Cohen, 1991).

\section{Psychological Interventions and the Immune System}

In this section, we outline the major psychological interventions that have appeared in the literature. By psychological interventions we mean interventions designed to improve psychological and/or physical well-being through the modification of emotion, cognition, or behavior (Cawley, 1983). We describe five broad classes of intervention: stress-management, relaxation, disclosure, hypnosis, and conditioning. In each case, we also present a theoretical model describing the major behavioral and biological pathways through which the intervention might influence the immune system. The overwhelming majority of existing trials have proceeded without such explicit theoretical frameworks to guide them. This represents a significant problem because, as we discuss later, such frameworks have important implications for how studies are designed, what participant populations are enrolled, which interventions are implemented, which immune functions are measured, which mediating pathways are tested, and to what situations they can be generalized. We should note at the outset, however, that our models are meant as organizing tools to guide work in this area. Very little evidence exists at this point to substantiate or refute them, and it is not our goal here to do so.

\section{Stress-Management Interventions}

Stress-management interventions attempt to alleviate the immune system dysregulation that accompanies psychological stress. Although it would be theoretically appropriate to administer these interventions to healthy persons in chronically stressful situations, the existing stress-management trials focus exclusively on patients undergoing treatment for medical illnesses such as cancer, HIV infection, and rheumatoid arthritis. This work is guided by the 
assumption that the illness represents a profound form of psychological stress. As we discuss later, this is not always a tenable assumption, as many people successfully adjust to chronic illness (Taylor, 1983; Taylor \& Brown, 1988).

Stress-management trials typically consist of four major components: illness education, cognitive restructuring, coping skills training, and the provision of psychological support. Detailed information about the content of these stress-management interventions can be found elsewhere (Antoni, 1993; Fawzy \& Fawzy, 1994; Kemeny \& Miller, 1999). How could an intervention of this nature influence the immune system? To answer this question, we outline a model positing that stress-management alleviates immune dysregulation by modifying psychobiological processes set into motion by stressful experience. This model begins with the notion that people continuously appraise ongoing stressful circumstances along dimensions of threat and manageability (Lazarus \& Folkman, 1984). To the extent that circumstances are evaluated as posing a significant threat and exceeding coping resources, they elicit negative emotional responses. These emotional responses give rise to coping efforts, which in some cases have direct effects on immunity. For instance, distressed individuals might cope by increasing tobacco or alcohol use, decreasing physical activity, or altering sleep patterns. These behaviors could conceivably modify immune responses (Cohen \& Williamson, 1991; Kiecolt-Glaser \& Glaser, 1988; Miller, Cohen, \& Herbert, 1999).

Negative emotional states also are hypothesized to modulate the immune system by activating the sympathetic division of the autonomic nervous system. Sympathetic fibers descend from the brain into both primary (bone marrow and thymus) and secondary (spleen and lymph nodes) lymphoid tissues. When activated by distress, these fibers release a wide variety of substances that could influence immune responses by binding to receptors on white blood cells (Ader, Cohen, \& Felten, 1995; Felten \& Felten, 1994; Kemeny, Solomon, Morley, \& Herbert, 1992; Rabin, 1999). Activation of hormonal systems constitutes another pathway through which negative emotions could induce immune dysregulation. Distress activates the hypothalamic-pituitary-adrenal axis, the sympathetic adrenal-medullary axis, and the hypothalamicpituitary-ovarian axis. The hormonal products of these systems can bind to specific receptors on white blood cells and induce changes in their function (Blalock, 1994; Rabin, 1999). With repeated exposure to these hormones, the immune response can become dysregulated, with altered patterns of cell trafficking, proliferation, and cytokine secretion.

A stress-management intervention could interrupt this process in several ways. First, it could modify the way that stressful circumstances are appraised. To the extent that it helps people to view their circumstances as less threatening, for example, cognitive restructuring could diminish the negative emotional responses that give rise to immune dysregulation. An intervention could also target negative emotions directly through activities like relaxation and emotion-regulation training. The importance of this pathway has been illustrated in several trials, each showing that the extent of immune system change covaries with reductions in negative emotion (Antoni et al., 1991; Fawzy, Cousins, et al., 1990; Lutgendorf et al., 1997). Apart from their stress-reducing functions, interventions could also influence immunity by providing people with increased social contact or teaching them more adaptive coping strategies. Both of these processes have been linked with immune outcomes (Lutgendorf et al., 1994; Segerstrom, Taylor, Kemeny, \& Fahey, 1998).

The model assumes that a stress-management intervention will be most successful at modulating immune responses when it meets three conditions. The first is that participants have encountered an immune-dysregulating stressful experience. Without such an impairment, the intervention is likely to fail because complex homeostatic mechanisms exist to prevent the inmune system from becoming overactive and initiating an attack on the self (KiecoltGlaser \& Glaser, 1992). The second condition is that the intervention successfully reduces stress. This process would involve eliciting more benign appraisals of the precipitating experience, reducing negative emotion, and modifying health-compromising behavior. The final condition is that the intervention attempts to modulate immune processes that are dysregulated by stressful experience. Of the many immune processes measured in this literature, only a subset have demonstrated sensitivity to stress and hence might be expected to change in the context of a successful intervention. Specifically, stress-related immune dysregulation is characterized by declines in circulating counts of various lymphocyte subpopulations including total T-cells, helper/inducer T-cells $\left(T_{H}\right)$, suppressor/cytotoxic $T$-cells $\left(T_{C}\right)$, natural killer cells $(N K)$, and $\mathbf{B}$ cells. Stress also elicits a reduction in total secretory immunoglobulin IgA (sIgA) and an increase in antibody titers to the herpesviruses EBV and HSV. (This change occurs because antibodies levels fluctuate directly with viral replication; antibodies are thus viewed as an indirect marker of viral activity.) Dysregulation of functional immune measures also accompanies stress and includes downregulation of natural killer cell cytotoxicity (NKCC) and lymphocyte proliferative responses to the mitogens concanavalin A (ConA), phytohemagglutinin (PHA), and pokeweed mitogen (PWM; Herbert \& Cohen, 1993).

\section{Relaxation Interventions}

Although many studies seek to alleviate stress-induced immune dysregulation through multifaceted stress-management interventions, others have attempted to do so through relatively straightforward relaxation interventions. These studies have used a wide variety of techniques including the relaxation response, progressive muscle relaxation, and biofeedback-assisted relaxation (Benson, 1993; Lehrer \& Woolfolk, 1993). How could interventions like these influence immune responses? We believe that the model described above can answer this question. In that model, circumstances appraised as threatening and exceeding coping resources elicit negative emotional states, which bring about immune dysregulation by activating hormonal systems and/or sympathetic fibers that innervate lymphoid organs. A relaxation intervention could alleviate this dysregulation by reducing negative emotion and consequently dampening activity in hormonal systems and/or relevant descending sympathetic fibers. There is considerable evidence that relaxation interventions are capable of yielding these effects. Studies have demonstrated, for example, that states of relaxation are accompanied by declines in negative mood states, sympathetic nervous system activity, and circulating hormone levels (Hoffman et al., 1982; Lehrer \& Woolfolk, 1993; McGrady et al., 1987). The model assumes that relaxation interventions will be most successful when they meet the same conditions as stressmanagement: enrolling participants who have encountered an 
immune-altering stressful experience, successfully altering the hypothesized psychobiological mediators, and measuring immune outcomes with demonstrated sensitivity to stress.

\section{Disclosure Interventions}

Theorists in the psychosomatic tradition have long maintained that adverse health consequences can result from the inhibition of psychologically significant thoughts and feelings (Pennebaker, 1995). Recently this view has given rise to studies examining whether interventions aimed at helping people to disclose previously inhibited material can improve well-being. These studies typically have participants write essays about a stressful experience that they have not discussed extensively with others (e.g., rape, incest, and personal failures). The writing takes place over a relatively short period of time (e.g., 15-30 min) on several consecutive days. In some instances the participants are asked to verbally disclose the experience rather than write about it (Esterling, Antoni, Fletcher, Margulies, \& Schneiderman, 1994; Lutgendorf et al., 1994).

How could a disclosure intervention of this nature influence the immune system? A model of this process begins with the assumption that people cope with some stressful experiences through psychological inhibition-the failure to express the thoughts, feelings, and behaviors that surround the experience. Inhibition occurs when people believe that they cannot easily discuss their experience with others, either because they do not trust them or fear that a discussion might have unpleasant consequences (Lepore, Silver, Wortman, \& Wayment, 1996). This inhibition exacts a toll on the immune system by activating hormonal systems and/or sympathetic fibers that innervate lymphoid organs (Pennebaker \& Beale, 1986). The disclosure process is hypothesized to alleviate the resulting immune dysregulation by forcing the individual to impose structure on the experience through words, a process that facilitates a less threatening appraisal, a greater sense of personal control, and the feeling that one can now successfully cope with the experience's personal or social ramifications. More benign appraisals can reduce negative emotion and facilitate greater discussion of the stressful experience, both of which should dampen hormonal and sympathetic activity and thereby restore immune regulation. Disclosure has been shown to yield benefits of this nature, including more benign appraisals, reduced negative affect, and declines in sympathetic activity (Esterling et al., 1994; Pennebaker, 1995; Smyth, 1998). Moreover, the extent of immune change after disclosure has been shown to covary with people's capacity to adopt more benign appraisals (Esterling et al., 1994).

This model suggests that disclosure interventions will have the greatest chance of successfully modulating immune responses when they (a) are delivered to people who are coping with a stressful life experience through psychological inhibition (b) bring about more benign appraisals and reduced negative affect, and (c) assess immune system parameters that become dysregulated with psychological inhibition.

\section{Hypnosis With Immune Suggestion Interventions}

Hypnosis is an altered state of consciousness marked by deeply focused attention and extreme sensitivity to suggestion. Its application to the immune system grew out of the series of studies performed in the early 1960s (Black, Humphrey, \& Niven, 1963; Black, 1963a, 1963b; Black \& Friedman, 1965). In a typical hypnosis with immune suggestion (HWIS) trial, the participant has an antigen pricked into his or her skin. Next, a hypnotic state is induced, followed by explicit suggestions that the immune system will not respond to the antigen. The wording of the suggestion varies across studies, with some suggesting that participants "imagine themselves taking a guided tour inside their own bodies" during which they "travel in the blood stream to their right arm" and encounter white blood cells. The cells, "knowing that the injected material only contained harmless proteins from dead bacteria" would "check the site of the injection but not react much further" (Zachariae, Bjerring, \& Arendi-Nielsen, 1989, p. 539). Others suggest that participants experience sensations of coolness, numbness, and dissociation in the arm (Laidlaw, Richardson, Booth, \& Large, 1994). In some studies, suggestions direct participants to enhance, rather than suppress, immune responses to the antigen.

It is not immediately clear how an intervention of this nature would operate. One possibility is that hypnosis interventions modulate the immune system by eliciting a state of relaxation. This process might reduce negative emotion, dampen activity in hormonal systems and/or the sympathetic fibers that innervate lymphoid tissue, and alter immunity through the pathways described earlier. If this were the case, we would expect hypnosis to yield the same immune alterations as relaxation, that is, an alleviation of any stress-induced immune dysregulation.

It is also conceivable that the hypnotic state enables people to modify biological processes in a fashion that facilitates the suggested immune alterations. Studies have shown that people can follow hypnotic suggestions to alter autonomically mediated processes such as heart rate, blood pressure, skin temperature, and even regional blood flow (Lehrer \& Woolfolk, 1993). Additionally, studies have shown that rodents can learn to control many of the visceral organs innervated by the autonomic nervous system, including the heart, the salivary glands, the intestines, the kidney, and the stomach (Miller, 1969). Collectively, these findings suggest that humans may have the necessary biological hardware (i.e., connections between the frontal cortex, the autonomic nervous system, the circulatory system, and visceral organs) to carry out immune-related hypnotic suggestions. It remains unclear, how. ever, whether they actually have the capacity to use this hardware. It has not been shown, for example, that people can successfully carry out hypnotic suggestions to modify circulating hormone levels. Even if they could, it is not evident how a person would "know" which biological mediators needed to be altered to facilitate a hypnotically suggested immune change.

Regardless of the specific mechanisms through which HWIS interventions operate, their success is likely to depend heavily on whether participants are susceptible to hypnotic induction. People vary dramatically in their capacity to achieve hypnotic states, and studies have shown that highly hypnotizable participants show greater immune change with hypnotic interventions than their low hypnotizable peers (Gregerson, Roberts, \& Amiri, 1996; Ruzyla-Smith, Barabasz, Barabasz, \& Warner, 1995; Zachariae, Hansen, et al., 1994; Zachariae, Jorgensen, Christensen, \& Bjerring, 1997). 


\section{Conditioning Interventions}

The application of conditioning principles to the immune system grew out of demonstrations that conditioned immunosuppression could be induced in rodents (Ader \& Cohen, 1975). Efforts to apply conditioning to the human immune system have generally involved administering an initially neutral, but highly salient, stimulus to participants (e.g., sherbet sweet; Buske-Kirschbaum, Kirschbaum, Stierle, Lehnert, \& Hellhammer, 1992; Kirschbaum et al., 1992) and then administering an immune-modulating agent (e.g., epinephrine). This pairing is carried out for several consecutive days, after which the participant is presented with the neutral stimulus alone, with the expectation that it will elicit the same immune response as it did when presented in the context of the immune-modulating agent.

A model of how this might occur can be generated on the basis of principles of classical conditioning. An initially neutral stimulus (called the conditional stimulus or CS) is paired with an immunemodulating stimulus (called the unconditional stimulus or UCS). With repeated presentation, the $\mathrm{CS}$ alone comes to elicit the same immunologic response as the UCS. The principal mediators of this phenomenon would probably be hormonal systems and/or the sympathetic fibers that innervate lymphoid organs. In other words, the initially neutral stimuli would come to elicit immune responses on their own by first bringing about changes in hormone secretion patterns and/or descending sympathetic fiber activity (BuskeKirschbaum et al., 1992). Studies have demonstrated that hormone secretion and sympathetically mediated biological processes (e.g., blood pressure and heart) can both be successfully conditioned (Lieberman, 1990; Stockhurst et al., 1999). On the basis of the literature on conditioned immunosuppression in animals (Ader \& Cohen, 1991), we suspect that the success of human conditioning interventions depends on having a sufficiently salient CS paired with a UCS that activates the relevant descending sympathetic fibers and/or hormonal systems, an adequate number of pairings of the CS and UCS, and the appropriate sequencing and timing of the stimulus presentations.

\section{The Meta-Analysis}

The major question our meta-analysis addresses is whether the psychological interventions described above can reliably modulate immune system parameters. When the necessary data are available, we also examine whether interventions show greater evidence of success when delivered to participants who possess theoretically important background characteristics. These background characteristics, identified on the basis of the models described earlier, include whether the participant has recently encountered a stressful experience and whether he/she has demonstrated susceptibility to hypnotic suggestion. Finally, we examine whether evidence exists for a dose-response relationship between various psychological interventions and the immune response. Such an effect might be especially likely to emerge in the context of skill-building interventions like stress-management, relaxation training, and hypnosis, where participants must develop proficiency with specialized techniques in order to successfully alter the psychobiological pathways described above. It is important to note that the moderator analyses we present here are preliminary in nature because in some cases the trials we review have only a modest degree of overlap in terms of the interventions they administer, the designs they use to test them, the background characteristics of the participants they enroll, and the immune outcomes they measure.

\section{Method}

\section{Identification of Studies}

The review was limited to studies of psychological interventions and the immune system. We noted earlier that psychological interventions are defined as efir.: to improve well-being through the modification of behavior, cogna or emotion. Studies that aimed to improve well-being by directly matomical and/or physiological processes (e.g., medication, $n:$ therapy, exercise therapy) were excluded from the review. We acs. iledge, however, that such interventions could operate, in part, by mod: ing psychological processes.

To identify sties, we performed computerized literature searches of the Medline and PsycINFO databases. The searches, performed in January, 2000 , used combinations of the following keywords: intervention, psychotherapy, disclosure, hypnosis, relaxation, biofeedback, conditioning, stressmanagement, leukocyte, lymphocyte, natural killer cell, psychoneuroimmunology, and immune function. We then used the ancestry method to compile lists of studies that had not been identified through initial computerized searches. We also hand-searched through post-1960 issues of seven journals that regularly publish research in the field of psychoneuroimmunology. They were Biofeedback \& Self-Regulation, Brain, Behavior \& Immunity, Health Psychology, International Joumal of Behavioral Medicine, Journal of Consulting and Clinical Psychology. Psychosomatic Medicine, and Psychotherapy \& Psychosomatics. We included only those articles published in English-language scientific journals.

The search procedures yielded a pool of 89 studies, which showed considerable variability in methodological quality. Because the validity of a meta-analysis rests on the quality of the studies it includes, we required that all trials meet two methodological eligibility criteria. The first criterion was that they were true experiments. To fulfill this criterion, a study was required to randomly assign participants to either an intervention or control condition in a between-groups design, or, in the context of a within-group design, participation in the intervention and control conditions had to be randomly ordered. The second criterion was that studies had to have multiple-subject designs.

When we applied these criteria, 23 studies were excluded from the pool for using nonexperimental designs (26\%), and 3 were excluded for singlesubject designs $(3 \%)$. Four other studies were subsequently excluded because they failed to report enough data for an effect size to be computed (Chapman, Goodell, \& Wolff, 1959; Ikemi \& Nakagawa, 1962) or had summarized or performed secondary analyses on data that was described in another report (Antoni, LaPerriere, Schneiderman, \& Fletcher, 1991; Hall, Minnes, \& Olness, 1993). These factors were problematic because metaanalysis proceeds on the assumption that each study contributing to the analyses is independent of the others (Rosenthal, 1991). A pool of 59 studies was left for the meta-analysis, reported in 55 separate journal articles. The Reference section lists all studies located in the search by inclusion/exclusion status, reason for exclusion, and intervention class.

\section{Meta-Analytic Procedures}

Meta-analysis is a tool for synthesizing research findings. It proceeds in two phases. In the first phase, effect sizes are computed for each study. An effect size represents the magnitude of the relationship between two variables, independent of sample size. In this context it can be viewed as a measure of how much an intervention and control group differ on a particular immune parameter at the end of treatment. In the second phase 
of meta-analysis, effect sizes derived from individual studies are combined to arrive at an aggregate effect size for each outcome of interest.

We conducted the meta-analysis on the basis of a fixed-effects model (Rosenthal, 1991; Shadish \& Haddock, 1994). We calculated effect sizes from individual studies using statistics published in the original reports. When these statistics were not included, and could not be obtained from the authors, we adopted a statistically conservative approach to estimation. When a trial failed to report statistical data, for example, but indicated that there were significant differences, we computed effect sizes assuming that $p$ values were equivalent to .05 . This process represents a conservative approach because the actual $p$ values were probably much smaller. Similarly, when a trial failed to report relevant statistics, but mentioned that groups did not differ with respect to an outcome, we assumed that there was no difference at all between the groups. Because there is seldom no difference at all between two groups, this process also represents a very conservative strategy.

The effect size estimates from individual studies were subsequently aggregated using the weighted Stouffer method, with degrees of freedom used as weights (Rosenthal, 1991; Shadish \& Haddock, 1994). This method yielded an aggregate weighted $r$ statistic for each immune outcome included in the meta-analysis. These statistics can be interpreted in the same fashion as a correlation coefficient, and are weighted in the sense that studies with larger samples contribute to the statistic to a greater extent than those with smaller ones. Weighting by sample size is important because larger studies provide more accurate estimates of true population parameters (Shadish \& Haddock, 1994).

After each aggregate effect size had been computed, we assessed whether it was statistically significant, arose from a heterogeneous group of trials, and stemmed from a publication bias toward positive findings. Following convention, aggregate effects were considered statistically different from zero when (a) their corresponding $z$ value was greater than zero and (b) the $95 \%$ confidence intervals around them did not include the value zero (Rosenthal, 1991; Shadish \& Haddock, 1994). To determine whether the studies contributing to each aggregate effect size shared a common population value, we computed the heterogeneity statistic $Q$ (Shadish \& Haddock, 1994). This statistic is chi-square distributed with $k-1$ degrees of freedom, where $k$ represents the number of independent effect sizes included. When a statistically significant $Q$ test emerged, we searched for moderators (participant background characteristics) that could explain the variability across studies. In some cases, however, the small number of trials contributing to an effect precluded us from examining sources of heterogeneity.

Because scientific joumals have a strong bias toward publishing positive findings, meta-analyses are generally thought to overestimate population effect sizes because an unknown number of studies with null findings exist and have not found their way into the published literature. We estimated the magnitude of this "file-drawer problem" by calculating the fail-safe $N$ statistic, which reflects the number of unpublished studies with null findings that would be needed to diminish an effect size from statistical significance to marginal significance. Rosenthal (Rosenthal, 1994) suggested that a file-drawer problem may exist when the fail-safe $N$ is less than five times the number of published studies plus ten. When this occurs, the finding should be viewed as a promising trend that needs conoboration. It is important to remember, however, that file-drawer problems will inevitably arise in meta-analyses of relatively small literatures because the statistic itself is computed on the basis of the number of published trials:

\section{Results}

\section{Preliminary Findings}

A total of 2,135 individuals participated in the 59 trials that comprised the meta-analysis. The trials examined stressmanagement (16\%), relaxation $(26 \%)$, disclosure (10\%), HWIS
(31\%), and conditioning interventions (10\%). Four trials ssed multiple-group designs where both relaxation and HWIS inte-rentions were evaluated $(7 \%)$.

In terms of background characteristics, only a minority of szessmanagement interventions (44\%) were delivered to populazions experiencing enduring psychological stressors. These stresso: included bereavement (Goodkin et al., 1998), diagnosis with a $=$ jor medical illness (Antoni et al., 1991; Fawzy et al., 1990), an the transition from the asymptomatic to symptomatic stage of :IV infection (Lutgendorf et al., 1997). All stress-management tials, however, were delivered to people with a chronic medical ilt-ess. As we mentioned earlier, chronic illness can, in some cises, represent a major source of psychological stress. The metical illnesses included cancer (20\%), HIV infection (60\%), and 亡eumatoid arthritis (20\%). A small minority of relaxation trials (10\%) were delivered to stressed populations, which in all cases =ere medical students facing examinations (Kiecolt-Glaser et al., 1\$86; Whitehouse et al., 1996). Another group of relaxation tria's focused on medical populations including those with cancer $(10 \%)$, HIV infection (10\%), and upper respiratory infections (5\%). The vast majority $(73 \%)$ of HWIS trials were delivered to preselezted participants who scored high on measures of hypnotic suscepability or reported previous success with hypnosis.

\section{Interpreting the Meta-Analytic Findings}

Tables 1-5 describe the meta-analytic results for each inter-ention. As we mentioned, the aggregate effect size $r$ can be itterpreted in the same fashion as a correlation, with values rarying from -1 to +1 . A useful rule of thumb for judging effect sizzs is to consider values of $.10, .30$, and .50 as corresponding to small, medium, and large-sized effects, respectively (Cohen \& Ccoen, 1983). Positive values indicate that an intervention increass a particular immune measure relative to a control condition. The only exception to this occurs in studies where participants are instructed to deliberately blunt their immune response to an antigen. For computational reasons, we had to assign these st-dies positive values when they found participants could success illy carry out hypnotic suggestions. All of the meta-analytic fincings we report reflect how psychological interventions relate to im-tne parameters immediately after treatment has ended; a meta-anz'ysis of follow-up outcomes was not possible because too few tials included assessments after the end of treatment. Finally, we stould caution the reader that in some analyses (particularly those examining moderator variables and dose-response relationships), our statistics are derived from as few as two independent stwies. Although analyses of this nature do not pose any major statiscical problems, the relatively small number of studies involved maies it difficult to appropriately evaluate statistical significance. Wiat a meta-analysis can accurately provide in these instances, howerer, is an estimate of how much a given intervention can influezce a particular immune outcome (i.e., an effect size estimate).

\section{Meta-Analyses of Stress-Management Interventions}

The meta-analyses of stress-management interventions are displayed in Table 1. Although a successful stress-managemer: intervention might be expected to alleviate the immune dysreglation that accompanies stress, the meta-analyses yield Etrle 
Table 1

Meta-Analyses of Stress-Management Interventions

\begin{tabular}{|c|c|c|c|c|c|c|c|c|}
\hline Immune parameter & Studies & $N$ & $\begin{array}{l}\text { Aggregate } \\
\text { effect size } r\end{array}$ & $\begin{array}{c}95 \% \text { confidence } \\
\text { interval }\end{array}$ & $Z$ & $\begin{array}{l}\text { Heterogeneity } \\
\text { statistic }\end{array}$ & Fail-safe $N$ & $\begin{array}{c}\text { File-drawer } \\
\text { issue? }\end{array}$ \\
\hline \multicolumn{9}{|l|}{$\begin{array}{l}\text { Leukocyte numbers } \\
\text { Lymphocytes }\end{array}$} \\
\hline Lymphocytes & 2 & 58 & .278 & $.01, .51$ & $2.06^{*}$ & $10.09 * *$ & 1 & Ýes \\
\hline $\mathrm{T}_{\mathrm{H}}$ lymphocytes & 7 & 262 & -.010 & $-.14, .11$ & -0.17 & 9.40 & & \\
\hline$T_{C}$ lymphocytes & 3 & 115 & .077 & $-.11, .26$ & 0.80 & 0.19 & & \\
\hline $\mathrm{T}_{\mathrm{H}} / \mathrm{T}_{\mathrm{C}}$ ratio & 4 & 267 & -.035 & $-.16, .09$ & -0.56 & 0.92 & & \\
\hline $\mathrm{T}_{\mathrm{H}}$ lymphocytes & \multicolumn{7}{|c|}{ Leukocyte percentages } & \\
\hline $\mathrm{T}_{C}$ lymphocytes & $\begin{array}{l}2 \\
2\end{array}$ & $\begin{array}{l}77 \\
77\end{array}$ & $\begin{array}{r}.039 \\
-.010\end{array}$ & $\begin{array}{l}\because .19, .27 \\
\because 24,24\end{array}$ & 0.33 & 0.16 & & \\
\hline Natural killer cells & 2 & 77 & -.100 & $\begin{array}{l}-.24, .24 \\
-.32, .13\end{array}$ & $\begin{array}{l}-0.06 \\
-0.85\end{array}$ & 0.05 & & \\
\hline \multicolumn{9}{|l|}{$\begin{array}{l}\text { Cellular functions } \\
\text { NKCC }\end{array}$} \\
\hline NKCC & 5 & 192 & .010 & $-.13, .16$ & 0.17 & 2.22 & & \\
\hline Proliferation to Con $\mathrm{A}$ & 3 & 107 & .006 & $-.19, .20$ & 0.06 & $6.82^{*}$ & & \\
\hline Proliferation to PHA & 2 & 77 & .184 & $-.04, .40$ & 1.57 & 1.35 & & \\
\hline Proliferation to PWM & 3 & 100 & .050 & $-.15, .25$ & 0.51 & 0.61 & & \\
\hline
\end{tabular}
Note. $\mathrm{T}_{\mathrm{H}}=\mathrm{T}$-helper; $\mathrm{T}_{\mathrm{C}}=\mathrm{T}$-cytotoxic/suppressor; $\mathrm{NKCC}=$ natural killer cell cytotoxicity; ConA $=$ concanavalin $\mathrm{A} ; \mathrm{PHA}=$ phytohemagglutinin;
$\mathrm{PWM}=$ pokeweed mitogen.

${ }^{*} p<.05 .{ }^{* *} p<.01$.

evidence of this. A reliable increase in total lymphocytes does emerge; however, this finding is unexpected because lymphocyte counts are generally not altered with stress. This finding also is subject to a file-drawer problem and is accompanied by a significant heterogeneity statistic. Contrary to expectations, the metaanalyses provide no evidence that stress-management interventions can modulate a variety of enumerative (cell numbers and percentages) or functional (NKCC and lymphocyte proliferative responses) outcomes that are known to decline with stressful experience.

The theoretical model we presented earlier suggests that stressmanagement may have the greatest success at modulating the immunity when delivered to people experiencing an enduring psychological stressor. To examine whether stress-management interventions perform better under these circumstances, we recomputed meta-analyses after stratifying participants by the presencel absence of an enduring stressor. Unfortunately, only four trials actually enrolled stressed populations. Although these trials did not have a sufficient degree of overlap in immune outcomes to permit a meta-analysis, each of them documented reliable immune alterations in the expected direction. These included increases in natural killer cell cytotoxicity (NKCC; Fawzy et al., 1990), the lymphocyte proliferative response to PHA (Antoni et al., 1991), and $T_{\mathbf{H}}$ counts (Antoni et al., 1991; Goodkin et al., 1998), as well

Table 2

Meta-Analyses of Relaxation Interventions

\begin{tabular}{|c|c|c|c|c|c|c|c|c|}
\hline Inmune parameter & Studies & $N$ & $\begin{array}{l}\text { Aggregate } \\
\text { effect size } r\end{array}$ & $\begin{array}{l}95 \% \text { confidence } \\
\text { interval }\end{array}$ & $Z$ & $\begin{array}{c}\text { Heterogeneity } \\
\text { statistic }\end{array}$ & Fail-safe $N$ & $\begin{array}{c}\text { File-drawer } \\
\text { issue? }\end{array}$ \\
\hline \multicolumn{9}{|l|}{ Leukocyte numbers } \\
\hline White blood cells & 4 & 108 & -.166 & $-.35, .03$ & -1.64 & 4.81 & & \\
\hline Granulocytes & 4 & 108 & -.189 & $-.39, .03$ & -1.72 & 4.66 & & \\
\hline Monocytes & 4 & 108 & -.124 & $-.31, .08$ & -1.22 & 3.67 & & \\
\hline Lymphocytes & 5 & 138 & -.086 & $-.26, .08$ & -1.04 & 1.35 & & \\
\hline $\mathrm{T}_{\mathrm{H}}$ lymphocytes & 2 & 104 & .125 & $-.07, .31$ & 1.25 & 0.64 & & \\
\hline $\mathrm{T}_{\mathrm{H}} \mathrm{T}_{\mathrm{C}}$ lymphocytes & 3 & 138 & .068 & $-.12, .12$ & 0.71 & 0.53 & & \\
\hline Natural killer cells & 2 & 104 & -.047 & $-.24, .14$ & 0.47 & 0.16 & & \\
\hline \multicolumn{9}{|l|}{ Total immunoglobulin levels } \\
\hline Total secretory IgA & 6 & 259 & .366 & $.25, .47$ & $5.97 * * *$ & $30.55 * * *$ & 73 & No \\
\hline & 2 & 64 & .000 & $-.25, .25$ & 0.00 & 0.01 & & \\
\hline \multicolumn{9}{|l|}{ Cellular functions } \\
\hline Proliferation to ConA & $\begin{array}{l}5 \\
4\end{array}$ & $\begin{array}{r}154 \\
86\end{array}$ & $\begin{array}{r}.135 \\
-050\end{array}$ & $-.02, .29$ & 1.65 & 6.01 & & \\
\hline Proliferation to PHA & 5 & $\begin{array}{r}80 \\
155\end{array}$ & $\begin{array}{r}-.050 \\
.130\end{array}$ & $-.24, .16$ & -0.48 & $21.55^{* * *}$ & & \\
\hline Proliferation to PWM & 3 & 100 & $\begin{array}{l}.130 \\
.000\end{array}$ & $\begin{array}{l}-.03, .29 \\
-.22 .22\end{array}$ & 1.55 & 8.17 & & \\
\hline \multicolumn{9}{|l|}{ Hypersensitivity responses } \\
\hline DTH induration & 2 & 113 & -.091 & $-.26, .09$ & -1.17 & 2.03 & & \\
\hline
\end{tabular}

Note. $\mathrm{T}_{\mathrm{H}}=\mathrm{T}$-helper; $\mathrm{T}_{\mathrm{C}}=\mathrm{T}$-cytotoxic/suppressor; $\mathrm{IgA}=$ immunoglobulin $\mathrm{A} ; \mathrm{NKCC}=$ natural killer cell cytotoxicity; ConA $=$ concanavalin $\mathrm{A} ;$ $\mathrm{PHA}=$ phytohemagglutinin; $\mathrm{PWM}=$ pokeweed mitogen; $\mathrm{DTH}=$ delayed-type hypersensitivity.
$* * * p<.001$ 
Table 3

Meta-Analyses of Disclosure Interventions

\begin{tabular}{|c|c|c|c|c|c|c|c|c|}
\hline Immune parameter & Studies & $N$ & $\begin{array}{c}\text { Aggregate } \\
\text { effect size } r\end{array}$ & $\begin{array}{c}95 \% \text { confidence } \\
\text { interval }\end{array}$ & $Z$ & $\begin{array}{c}\text { Heterogeneity } \\
\text { statistic }\end{array}$ & Fail-safe $N$ & $\begin{array}{l}\text { File-draxer } \\
\text { issue? }\end{array}$ \\
\hline \multicolumn{9}{|l|}{ Leukocyte numbers } \\
\hline$T_{H}$ lymphocytes & 2 & 78 & -.309 & $-.50,-.08$ & $-2.71 * *$ & 0.41 & \multirow[t]{2}{*}{3} & \multirow[t]{2}{*}{ Yes } \\
\hline $\begin{array}{l}T_{C} \text { lymphocytes } \\
\text { Herpesvirus antibody titers }\end{array}$ & 2 & 78 & -.157 & $-.37, \quad .07$ & -1.34 & 0.40 & & \\
\hline Epstein-Barr virus & 2 & 116 & -.285 & $-.44,-.10$ & $-2.99 * *$ & $9.90^{* * *}$ & 4 & Yes \\
\hline
\end{tabular}

Note. $\mathrm{T}_{\mathrm{H}}=\mathrm{T}$-helper; $\mathrm{T}_{\mathrm{C}}=\mathrm{T}$-cytotoxic/suppressor.

${ }^{* *} p<.01$.

as a decline in antibody titers to the HSV (Lutgendorf et al., 1994). These effects were small to medium-sized, with $r$ ranging from .15 to .40 .

It is also possible that stress-management interventions are most successful in the context of certain medical illnesses. They might be especially beneficial for people suffering from HIV infection, for instance, given the significant financial, medical, legal, and treatment-compliance challenges this illness poses. When we examined this hypothesis, however, meta-analyses yielded no evidence that the efficacy of stress management varied across cancer, HIV infection, or rheumatoid arthritis (data not shown). In fact, there was no indication that stress-management elicited any reliable immune system alterations in any of these medical populations (data not shown).

A final possibility is that stress management has dose-dependent effects on the immune system. If, for instance, proficiency with cognitive restructuring and relaxation is a prerequisite for successful distress reduction, trials that provide the most exposure to these techniques could conceivably have the greatest chance of documenting immune modulation. To examine this, we recomputed the meta-analyses after stratifying trials according to the number of hours of treatment they provided (less than 10 vs. $10-20$ vs. 20 or more). These analyses provided no evidence, however, of a doseresponse relationship between the length of time spent in stressmanagement and any immune outcome (data not shown). We also performed analyses treating hours of treatment as a continuous variable and again found no support for a dose-dependent effect (data not shown).

\section{Meta-Analyses of Relaxation Interventions}

The meta-analyses addressing the impact of relaxation interventions on immune responses are presented in Table 2. Although a successful relaxation intervention might be expected to elicit a wide variety of immune alterations, the meta-analyses find very little evidence of this. Relaxation shows a reliable positive association with total $\operatorname{sgA}$ concentration but is unrelated to a variety of stress-sensitive enumerative ( $T ; T_{H}$, and natural killer cells) and functional (NKCC and lymphocyte proliferation) outcomes. The IIgA effect is also accompanied by a significant heterogeneity statistic.

The relaxation model we presented suggests that these interventions should show the greatest evidence of success when delivered to stressed populations. We were not able to examine this hypothesis meta-analytically, however, because only two of the relaxation trials enrolled stressed individuals, and they had insufficient overlap on immune outcomes. Neither trial showed evidence of eliciting reliable immune changes, however (Kiecolt-Glaser et al., 1986; Whitehouse et al., 1996). When the definition of psychological stress was broadened to include people with chronic medical illness, there was no evidence that relaxation had a differential impact among the broadly versus nonstressed participants (data not

Table 4

Meta-Analyses of Hypnosis With Immune Suggestion Interventions

\begin{tabular}{|c|c|c|c|c|c|c|c|c|}
\hline Immune parameter & Studies & $N$ & $\begin{array}{l}\text { Aggregate } \\
\text { effect size } r\end{array}$ & $\begin{array}{l}95 \% \text { confidence } \\
\text { interval }\end{array}$ & $Z$ & $\begin{array}{l}\text { Heterogeneity } \\
\text { statistic }\end{array}$ & Fail-safe $N$ & $\begin{array}{c}\text { File-drawer } \\
\text { issue? }\end{array}$ \\
\hline \multicolumn{9}{|c|}{$\begin{array}{l}\text { Total immunoglobulin levels } \\
\text { Total secretory IgA }\end{array}$} \\
\hline $\begin{array}{l}\text { Total secretory IgA } \\
\text { Cellular functions }\end{array}$ & 4 & 200 & .147 & $.01, .28$ & $2.03 *$ & 1.73 & 2 & Yes \\
\hline Proliferation to PHA & 3 & 93 & .022 & $-.19, .23$ & 0.22 & 0.10 & & \\
\hline Proliferation to $\mathrm{VZ}$ & 2 & 77 & .000 & $-.24, .24$ & 0.00 & 0.01 & & \\
\hline Neutrophil adherence & 2 & 55 & .503 & $.27, .68$ & $3.86 * * *$ & $6.17^{*}$ & 3 & Yes \\
\hline \multicolumn{9}{|l|}{ Hypersensitivity responses } \\
\hline ITH erythema & 8 & 123 & .231 & $.04, .41$ & $2.34^{*}$ & 9.11 & 12 & Yes \\
\hline ITH induration & 6 & 103 & .165 & $-.04, .36$ & 1.54 & 8.39 & & \\
\hline $\begin{array}{l}\text { DTH erythema } \\
\text { DTH induration }\end{array}$ & $\begin{array}{l}2 \\
7\end{array}$ & $\begin{array}{r}34 \\
176\end{array}$ & $\begin{array}{l}.257 \\
.080\end{array}$ & $\begin{array}{l}-.11, .56 \\
-.07, .23\end{array}$ & $\begin{array}{l}1.39 \\
1.02\end{array}$ & $\begin{array}{l}0.01 \\
2.23\end{array}$ & & \\
\hline
\end{tabular}
Note. $\quad$ ITH $=$ immediate-type hypersensitivity; $\mathrm{IgA}=$ immunoglobulin $\mathrm{A} ; \mathrm{PHA}=$ phytohemagglutinin; $\mathrm{VZ}=$ varicella zoster; DTH $=$ delayed-type
hypersensitivity.

${ }^{*} p<.05 . \quad * * * p<.001$. 
Table 5

Meta-Analysis of Conditioning Interventions

\begin{tabular}{lccccccc}
\hline $\begin{array}{l}\text { Immune parameter } \\
\text { Cellular functions }\end{array}$ & Studies & $N$ & $\begin{array}{c}\text { Aggregate } \\
\text { effect size } r\end{array}$ & $\begin{array}{c}95 \% \text { confidence } \\
\text { interval }\end{array}$ & $Z$ & $\begin{array}{c}\text { Heterogeneity } \\
\text { statistic }\end{array}$ & $\begin{array}{c}\text { File-drawer } \\
\text { Fail-safe } N\end{array}$ \\
$\quad$ NKCC & 4 & 62 & .574 & $.36,73$ & $4.62 * * *$ & 1.48 & 18 \\
\hline
\end{tabular}

Note. $\mathrm{NKCC}=$ natural killer cell cytotoxicity.

$* * * p<.001$.

show'n). When meta-analyses were stratified by illness, we also found no evidence that the efficacy of relaxation differed across cancer versus HIV or that reliable immune alterations occurred in either disease setting (data not shown).

Despite the fact that there was considerable variability across trials in the amount of time participants practiced relaxation (ranging from less than $1 \mathrm{hr}$ to $23 \mathrm{hr}$ ), analyses provided no support for a dose-response relationship with any of the immune outcomes (data not shomn)

\section{Meta-Analyses of Disclosure Interventions}

Table 3 describes the meta-analyses of disclosure interventions. Only three outcomes were examined in these analyses: $T_{\mathbf{H}}$ cell counts, $T_{C}$ cell counts, and antibodies to EBV. Given findings in the stress and immunity literature (Herbert \& Cohen, 1993), we would expect a successful disclosure trial to elicit higher cell counts and a reduction in antibody titers. The meta-analyses provide mixed evidence for this prediction. A reliable decline in EBV antibody titers emerges following disclosure, but this effect must be viewed as preliminary because it is subject to a file-drawer problem and is accompanied by a significant heterogeneity statistic. The meta-analyses also document a reliable $T_{H}$ cell decline following disclosure. However, this finding is subject to a filedrawer probiem and is in the opposite direction of what would be expected from the stress literature. Contrary to expectations, the meta-analysis finds no evidence that disclosure alters $T_{C}$ counts. With regard to dose-response effects, there was not sufficient variability actoss trials in the amount of time spent disclosing to permit a test of this hypothesis.

\section{Meta-Analyses of Hypnosis With Immune Suggestion Interventions}

The meta-analyses examining HWIS interventions are displayed in Table 4. When interpreting these findings, it is important to remember that participants were given hypnotic instructions to modify their immune response in a specified direction. Significant findings, therefore, reflect success at carrying out these instructions. The mata-analysis finds that HWIS interventions are associated with a reliable increase in both secretory IgA and neutrophil adherence. These findings should be viewed as preliminary, however, because they are subject to file-drawer problems. The effect for neutrophil adherence also is accompanied by a significant heterogeneiry statistic.

The meta-analyses also document a reliable change in the magnitude of ergthema associated with the immediate-type hypersensitivity (ITH) response. This effect derives primarily from situa- tions where participants are hypnotically instructed to suppress the immune response $(r=.271, z=2.66, p<.01)$, and not from situations where they are instructed to enhance it $(r=.00, n s)$. The difference in effect-size magnitude for suppression versus enhancement manipulations is statistically reliable, $z=1.99, p<$ .05. These effects, however, are subject to file-drawer problems. No evidence emerges that HWIS interventions can modulate induration associated with $\Gamma \mathrm{TH}$, regardless of whether the manipulation involves suppression or enhancement. The meta-analyses also provide no evidence that delayed-type hypersensitivity (DTH) can be reliably altered, irrespective of the manipulation (suppress vs. enhance), and whether the response is measured in terms of erythema or induration.

We suggested earlier that the success of HWIS interventions would depend on hypnotizability status. To examine this prediction, we recomputed meta-analyses after stratifying participants according to whether they were low versus high in hypnotizability. Sufficient data for this analysis was available for only two immune outcomes, the ITH and DTH responses. With respect to ITH, we found that highly hypnotizable participants modulated both erythema $(r=.388, z=3.03, p<.01)$ and induration $(r=.319$, $z=2.12, p<.05)$ in a reliable fashion. These effects emerged during attempts to carry out suppression rather than enhancement manipulations (for erythema, suppression $r=.419, z=3.09, p<$ .01 , enhancement $r=.000$, ns; for induration, suppression $r=$ $.321, z=2.13, p<.05$, enhancement $r=.000, n s$ ). Low hypnotizable participants, in contrast, showed no evidence of modulating these parameters (erythema $r=.020, n s$.; induration $r=.010, n s$ ). With respect to DTH, there was no evidence that high hypnotizable status was linked with the capacity to modulate induration or erythema $(r s<.030, n s)$.

HWIS trials differed considerably in the amount of time they required participants to practice before a hypnotic instruction to alter the immune response was provided (from no time at all up to $6 \mathrm{hr}$ ). However, meta-analyses provided no support for a dosedependent relationship between practice time and successful immune modulation (data not shown).

\section{Meta-Analyses of Conditioning Interventions}

Table 5 displays findings for the conditioning interventions. The meta-analysis indicates that conditioning interventions can reliably increase NKCC. Although this finding is in the expected direction (the interventions were all designed to increase $\mathrm{NKCC}$ ), it is subject to a file-drawer problem and should be viewed as preliminary. There was not sufficient variability across trials in exposure to conditioning procedures to allow a test of the dose-response relationship. 


\section{Discussion}

\section{Summary and Integration of Findings}

Stress-management interventions. Although stress-management interventions were expected to alleviate the immune dysregulation that accompanies psychological stress, little evidence of this emerged from the meta-analysis. Aside from an unexpected positive association with lymphocyte counts, these interventions showed no evidence of reliably altering immune outcomes, even those with known sensitivity to psychological stress. The model we presented earlier provides a clear explanation for these null findings, suggesting that stress-management interventions will only modulate immunity when delivered to people experiencing enduring psychological stress. Only a small minority of the trials actually enrolled populations of this nature, and perhaps not surprisingly, they elicited reliable immune alterations in expected directions (Antoni et al., 1991; Fawzy et al., 1990; Goodkin et al., 1998; Lutgendorf et al., 1997).

Relaxation interventions. Relaxation interventions also were expected to ameliorate stress-induced immune dysregulation. They showed little evidence of doing so, however, aside from eliciting a medium-sized increase in total sIgA concentration. The model we presented suggests that these modest effects may be attributable to the fact that only a small minority of the relaxation trials were administered to stressed populations. Even these trials did not yield evidence of reliable immune change, however, suggesting that people undergoing medical school examinations and chronic illness may not be a good candidate for future trials in this area.

Disclosure interventions. Disclosure interventions showed some evidence of success in the meta-analysis, yielding a reduction in antibody titers to EBV. This finding provides indirect evidence that disclosure can enhance the body's control over latent HSV production. A reliable decline in $T_{H}$ cell counts also occurred with disclosure interventions. However, this finding was in the opposite direction of what might be expected on the basis of the stress literature.

Hypnosis with immune suggestion interventions. The metaanalysis yielded some evidence that participants could successfully carry out hypnotic suggestions to modulate immune responses. It documented reliable increases in total $\operatorname{sigA}$ concentration and neutrophil adherence, effects that were medium- and large-sized, respectively. A small effect for ITH erythema also emerged, showing that people could follow hypnotic suggestions to suppress this response. When analyses were restricted to participants scoring high in hypnotizability, the erythema effect became even more pronounced, and a parallel finding emerged for induration. Despite their success at altering the ITH response, hypnotic interventions showed no evidence of modulating DTH. An intervention would not necessarily be expected to have identical effects on these responses, however, as they are mediated by different immunologic processes. ITH is an antibody-mediated response, whereas DTH is a cell-mediated process that involves $T_{H}$ and $T_{C}$ lymphocytes.

These findings may shed preliminary light on the mechanisms underlying hypnosis. Earlier we suggested that HWIS interventions could operate by eliciting relaxation. To the extent that this was correct, we argued that they should elicit the same pattern of immune system changes that emerges with relaxation, that is, a reversal of stress-induced immune dysregulation. The metaanalyses yielded evidence to support this prediction, as participants demonstrated the capacity to suppress, but not enhance, the ITH response. Given that acute psychological stress enhances the hypersensitivity response (Dhabar \& McEwen, 1997), these findings can be viewed as consistent with the notion that HWIS interventions influence the immune system through relaxation. However, stress-induced enhancement of the hypersensitivity response has only been demonstrated in the context of DTH, and further work will be needed to determine whether this phenomenon occurs with ITH.

Conditioning interventions. The meta-analysis demonstrated that conditioning interventions can enhance NKCC. This finding constitutes preliminary evidence that the robust conditioning effects observed in animals (Ader \& Cohen, 1991) can be extended to human beings. It will be important for future trials to substantiate this finding by examining functional immune parameters other than NKCC, and determining whether conditioning trials can be used to both increase and decrease immune functions, as theoretical models suggest they should.

Dose-response relationships. We expected a dose-response relationship to emerge between psychological interventions and immune outcomes, particularly in the context of treatments that required the acquisition of skills. The meta-analyses, however, did not yield evidence of such a relationship. It is possible that the small number of trials that had overlapping intervention strategies and immune outcomes precluded us from adequately testing this hypothesis. However, there has generally been mixed support for dose-response effects in this literature, with some studies finding more pronounced immune alterations among participants who practice relaxation more frequently (Antoni et al., 1991; KiecoltGlaser et al., 1986) and others finding no such association (Lutgendorf et al., 1997; O'Leary, Shoor, Lorig, \& Holman, 1988; Whitehouse et al., 1996). It is not clear what accounts for these discrepancies, or for our failure to document dose-response relations. It may be that the measure of dose used in this literature (the number of hours spent practicing or in treatment) does not capture whether participants have actually mastered the relevant skills.

\section{Where Do We Go From Here? Shaping the Next Wave of Trials}

Although the meta-analyses show that psychological interventions can modulate certain features of the immune response, their findings are considerably more narrow than might have been anticipated. Many enumerative and functional immune outcomes with documented sensitivity to stress showed no pattern of association with any intervention. Of the immune alterations that were observed, sIgA was the only outcome to change across two different interventions. And finally, the meta-analyses yielded no support for the claim that psychological interventions can induce beneficial immune changes in medical populations (Bock \& Sabin, 1997; Epstein, 1989; Levine, 1991). There was no evidence, for example, that $T_{H}$ cell counts could be increased in the context of HIV infection.

Why have existing intervention trials yielded such modest effects? One possibility, of course, is that the immune system is unresponsive to psychological interventions. Although the metaanalytic findings are generally consistent with this conclusion, we 
believe that it is premature. This area has a number of important conceptual and methodological issues that need to be resolved before any definitive conclusions can be reached. In the upcoming sections, we discuss these limitations and how they might best be addressed in the next wave of trials.

Enrolling appropriate participant populations. Researchers can substantially strengthen this literature by enrolling theoretically appropriate participant populations in the next wave of intervention trials. The most promising candidates for stressmanagement and relaxation interventions are people experiencing ongoing, severe, and chronic stressors with a demonstrated impact on the immune system. Several such groups have been identified, including victims of natural disasters (Ironson et al., 1997; McKinnon, Weisse, Reynolds, Bowles, \& Baum, 1989; Solomon, Segerstrom, Grohr, Kemeny, \& Fahey, 1997); the bereaved (Bartrop, Luckhurst, Lazarus, Kiloh, \& Penny, 1977; Irwin, Daniels, Smith, Bloom, \& Weiner, 1987; Schleifer, Keller, Camerino, Thomton, \& Stein, 1983); spouses experiencing chronic marital distress, separation, or divorce (Kiecolt-Glaser et al., 1987; Kiecolt-Glaser et al., 1988); and family caregivers for patients with neurological disease (Kiecolt-Glaser, Dura, Speicher, Trask, \& Glaser, 1991).

The vast majority of stress-management and relaxation interventions to date have been administered to medically ill patients. Although chronic illness can represent a powerful stressor, there are two potentially important limitations of this approach. The first is the risk that intervention-related immune changes will be obscured by more powerful biological forces (e.g., disease exacerbations, treatment protocols) acting on patients' immune systems. The second is the risk that not all patients will view illness as a significant stressor. Many people successfully adjust to chronic medical illness and even achieve a quality of life that exceeds their premorbid level (Taylor, 1983; Taylor \& Brown, 1988). For these reasons, it may be most fruitful to deliver the next wave of stress-management and relaxation trials to healthy individuals experiencing the stressors described above. If these interventions can reliably ameliorate immune dysregulation in healthy persons, follow-up trials in the context of medical illness would be appropriate. When such trials are conducted, however, they should be planned around stressful transitions in the disease process such as diagnosis, the onset of disfiguring and painful treatments, or the progression from clinically latent disease to full-blown AIDS. Studies adopting this approach have had much greater success documenting immune changes (Antoni et al., 1991; Fawzy et al., 1990; Lutgendorf et al., 1997) than those enrolling heterogeneous groups of patients at different disease stages (Richardson et al., 1997; Taylor, 1995).

We do not view people undergoing acutely stressful experiences as promising candidates for the next wave of stress-management and relaxation trials. These experiences induce transient immune alterations in only a subset of people (Whitehouse et al., 1996), and as a result, it may be difficult for trials to detect stress-buffering effects even when they do occur. The few trials planned around acute stressors have borne this out, failing to produce immune alterations in medical students taking exams (Kiecolt-Glaser et al., 1986; Whitehouse et al., 1996).

The disclosure model we presented suggests that such interventions will stand the best chance of modulating the immune system when they are delivered to individuals who are using psychological inhibition to cope with a personally stressful experience. To facilitate this, investigators should instruct participants to disclose experiences they have not previously shared with others. This approach was effective in an early study, which showed that the greatest improvements in lymphocyte proliferation occurred among individuals who had not previously shared their experience with others (Pennebaker, Kiecolt-Glaser, \& Glaser, 1988).

HWIS trials can clearly maximize their chances of success by enrolling highly hypnotizable participants. This fact has been documented in numerous studies (Gregerson et al., 1996; RuzylaSmith et al., 1995; Zachariae, Hansen, et al., 1994; Zachariae et al., 1997 ) and was confirmed in our meta-analysis.

On the basis of the promising data for conditioning interventions, we encourage researchers to extend this work into the clinical domain. A provocative case study with a pediatric lupus patient suggests that such efforts may have the potential to be clinically useful (Olness \& Ader, 1992). Aside from lupus, other immune-mediated conditions that seem promising to explore include dermatological and allergic diseases of mild severity.

Choosing appropriate immune system measures. Another way researchers can strengthen this literature is to select appropriate measures of immunity. Appropriate measures are those that have a straightforward directional interpretation, are sensitive to psychological modulation, have kinetics that match those of the intervention, and when collected in context of a medical illness, have demonstrated relevance for health. Generally speaking, we view functional immune measures as more appropriate choices than enumerative ones because we have a better understanding of what they represent. An important exception to this point occurs in $\mathrm{HIV}$ infection, where $T_{H}$ lymphocyte counts are a recognized marker of disease progression. Although several of the functional measures we discuss in this article have documented sensitivity to stress (NKCC, mitogen-stimulated lymphocyte proliferative response), it will be important for future trials to increase the use of in vivo measures. This research could be accomplished by examining antibody responses to vaccination (e.g., Petrie et al., 1995), ITH and DTH responses, or wound healing. The latter measure assesses the immune system's capacity to repair experimentally administered wounds (Kiecolt-Glaser, Marucha, Malarkey, Mercado, \& Glaser, 1995; Marucha, Kiecolt-Glaser, \& Favagehi, 1998). With hypersensitivity and wound-healing measures, it is possible to biopsy tissue sections where the response is unfolding and examine them for the presence of hormones and immune components. Studying these processes in local environments can yield valuable information that would not be available from peripheral blood (see Cohen, Doyle, \& Skoner, 1999; Glaser et al., 1999). Even though our meta-analyses found that total SIgA can be modulated by both relaxation and HWIS interventions, we do not recommend using this measure in the next wave of trials. Interpreting it is very difficult because SIgA concentration tends to be confounded with salivary flow rate. Also, because antibodies operate in an antigenspecific fashion, the meaning of total (nonspecific) immunoglobulin measures is unclear (Stone, Cox, Valdimarsdottir, \& Neale, 1987).

Another issue that investigators must consider when selecting immune outcomes is how well the temporal kinetics of potential measure match those of the intervention being debvered. Trials examining the acute effects of relaxation, for example, will maximize their chances of success by selecting rapidly changing immune processes (e.g., NKCC, immediate-type hypersensitivity). 
Trials studying longer-term interventions such as stressmanagement, however, would profit from selecting processes that unfold over a longer period of time, and are not susceptible to short-term perturbations (e.g., antibody responses to vaccinations; see review by Cohen, Miller, \& Rabin, in press).

Finally, the selection of immune measures should depend, to a large extent, on the subject population being studied. Trials with medical populations should use measures with demonstrated relevance for disease progression. Concentrations of proinflammatory cytokines, for instance, could have implications for infectious disease, atherosclerosis, wound healing, and autoimmune disease (Cohen et al., 1999; Glaser et al., 1999; Luster, 1998; Mendall et al., 1997; Rabin, 1999). There is also evidence that specific patterns of cytokine secretion (such as those that promote antibodymediated responses) play an important role in the exacerbation of asthma and allergic conditions, whereas others (such as those that promote cell-mediated responses) have relevance for the course of multiple sclerosis and rheumatoid arthritis (Luster, 1998; Rabin, 1999; Whitacre, Reingold, \& O'Looney, 1999; Wright, Rodriquez, \& Cohen, 1998). Investigators should consider these issues carefully as they select immune outcomes for intervention trials.

Designing methodologically rigorous studies. A number of steps could be taken to methodologically strengthen the next wave of intervention trials. These include using appropriate experimental designs, incorporating follow-up assessments after treatment has ended, ensuring that interventions have the intended effects on relevant psychological outcomes, and maximizing statistical power by increasing sample sizes and enhancing the reliability of immune measures. The most appropriate design for intervention trials is the completely randomized experiment. It has a straightforward interpretation and provides the field with a much-needed opportunity to test causal hypotheses about relations between psychological processes and the immune system. Future trials also should incorporate follow-up assessments, as stress-management and disclosure studies have found that intervention-related immune system differences become more pronounced with time (Fawzy et al., 1990; Petrie et al., 1995). These findings have potentially important implications because they suggest that immune changes may persist months after the formal intervention has ended.

The next wave of interventions also needs to routinely examine whether they are having the intended impact on psychological outcomes. This strategy will be especially important in the context of stress-management, relaxation, and disclosure trials, where immune alterations are hypothesized to stem from changes in the way that people appraise stress, experience negative emotion, and cope with difficulties in their lives. Several trials have demonstrated this empirically, showing that immune alterations only emerge to the extent that people display relevant changes in cognition (Esterling et al., 1994) and emotion (Antoni et al., 1991; Fawzy et al., 1990; Lutgendorf et al., 1997).

Statistical power represents another design feature that warrants careful consideration. To achieve a sense of the sample size needed for an intervention trial, let us examine a medium-sized effect of $r=.30$. This value corresponds roughly to the significant effects seen in the meta-analysis and thus can be viewed as a likely upper-bound estimate of the extent to which interventions might alter the immune response. Assuming effects of this magnitude, a trial would need 90 participants ( 45 per group) to have sufficient statistical power $(.80)$ to detect posttreatment immune differences between an intervention and control group. Only three of the trials we reviewed enrolled this many participants, and each documented reliable immune changes (Goodkin et al., 1998; Gregerson et al., 1996; Hewson-Bower \& Drummond, 1996). The average sample size of trials we reviewed, in fact, was 36 . This translates into statistical power of approximately .42 , suggesting that future trials will need to substantially boost enrollment if they wish to have adequate power to detect immune effects.

Another strategy for boosting statistical power involves enhancing the reliability of immune measures. Functional measures like the lymphocyte proliferation assay are plagued by notoriously high levels of measurement error. This problem can be circumvented to some extent by aggregating immune values across multiple assessments. This strategy works by minimizing the random error that arises from both natural biological variation and laboratory variance (Miller et al., 1999). Statistical power also can be enhanced by reducing laboratory variance. To accomplish this, laboratory control samples can be run alongside experimental samples. The effects of measurement error can then be covaried out in statistical analyses (Schleifer, Eckholdt, Cohen, \& Keller, 1993). Investigators also can collect samples from intervention and control group members simultaneously (Kiecolt-Glaser \& Glaser, 1988). These strategies will have a less profound influence on power, however, as they do not minimize the error associated with natural biological variation.

Hypersensitivity measurements are also plagued by high levels of measurement error. A variety of factors can influence the extent of induration and erythema that develops following antigen injection, including history of exposure, mood, arousal, and even the ambient temperature (Laidlaw et al., 1994; Laidlaw, Booth, \& Large, 1994). Controlling these factors, either through design or statistical analysis, can increase statistical power substantially. Because a considerable amount of measurement error is introduced when hypersensitivity is assessed from a single reaction, trials can also boost statistical power by assessing multiple reactions simultaneously. This process can be accomplished by administering multiple doses of a single antigen, or alternatively, multiple antigens (Laidlaw et al., 1994; Laidlaw, Booth, \& Large, 1996; Locke et al., 1987; Locke et al., 1994).

Testing mediational pathways. Researchers could also substantially strengthen this literature by assessing hypothesized mechanisms and conducting appropriate tests of statistical mediation. The models presented earlier suggest the appropriate pathways for each model. Readers can find an extensive discussion of measurement issues involved in assessing these pathways in a recent text (Cohen, Kessler, \& Underwood, 1995) and nontechnical overviews of statistical techniques for testing mediation in any of several articles (Baron \& Kenny, 1985; Hoyle \& Smith, 1994; Stone, 1992).

\section{Conclusions}

This article began with a description of the immune changes seen in several provocative intervention studies (Black, 1963a; Fawzy et al., 1990; Fawzy et al., 1993; Kiecolt-Glaser et al., 1985; Petrie et al., 1995). Although the meta-analyses show that these trials are not representative of the literature as a whole, we view them as an indication that, under the appropriate conditions, interventions may have the capacity to bring about reliable immune 
alterations. We cannot be certain of this, of course, and the analyses we report do not provide much cause for optimism. Nevertheless, we anticipate that if the next wave of trials can address the conceptual and methodological issues we have identified, they will be in an excellent position to document any clinical, theoretical, or practical implications of research on psychological interventions and the immune system.

\section{References}

References marked with an asterisk indicate studies included in the meta-analysis. References marked with two asterisks indicate studies located in the literature search but excluded from the meta-analysis.

**Achterberg, J., McGraw, P., \& Lawlis, G. F. (1981). Rheumatoid arthritis: A study of relaxation and temperature biofeedback training as adjunctive therapy. Biofeedback and Self-Regulation, 6, 207-223. [Excluded-Nonexperimental design]

Ader, R., \& Cohen, N. (1975). Behaviorally conditioned immunosuppression. Psychosomatic Medicine, 37, 333-340.

Ader, R., \& Cohen, N. (1991). The influence of conditioning on immune responses. In R. Ader, D. Felten, \& N. Cohen (Eds.), Psychoneuroimmunology (pp. 611-646). New York: Academic Press.

Ader, R., Cohen, N., \& Felten, D. (1995). Psychoneuroimmunology: Interactions between the nervous system and the immune system. Lancet,
$345,99-103$.

Antoni, M. H. (1993). Stress management: Strategies that work. In D. L. Goleman \& J. Gurin (Eds.), Mind-body medicine (pp. 385-400). Yonkers, NY: Consumer Reports Books.

*Antoni, M. H., Baggett, L., Ironson, G., LaPerriere, A., August, S., Klimas, N. G., Schneiderman, N., \& Fletcher, M. A. (1991). Cognitivebehavioral stress management intervention buffers distress responses and immunologic changes following notification of HIV-1 seropositivity. Journal of Consulting and Clinical Psychology, 59, 906-915. [Stress-management intervention]

**Antoni, M. H., LaPerriere, A., Schneiderman, N., \& Fletcher, M. A. (1991). Stress and immunity in individuals at risk for AIDS. Stress Medicine, 7, 35-44. [Excluded-Duplicate data]

**Ametz, B. B., Wasserman, J., Petrini, B., Brenner, S. O., Levi, L., Eneroth, P., Salovaara, H., Hjelm, R., Salovaara, L., Theorell, T., \& Petterson, I. L. (1987). Immune function in unemployed women. Psychosomatic Medicine, 49, 3-12. [Excluded-Nonexperimental design]

Baron, R. M., \& Kenny, D. A. (1985). The mediator-moderator variable distinction in social psychological research: Conceptual, statistical, and strategical considerations. Joumal of Personality and Social Psychology, 51, 1173-1182.

Bartrop, R. W., Luckhurst, E., Lazarus, L., Kiloh, L. G., \& Penny, R. (1977). Depressed lymphocyte function after bereavement. Lancet, $I$, 834-836.

*Beahrs, J. O., Harris, D. R., \& Hilgard, E. R. (1970). Failure to alter skin inflammation by hypnotic suggestion in five subjects with normal skin reactivity. Psychosomatic Medicine, 32, 627-631. [HWIS intervention]

Benjamini, E., Sunshine, G., \& Leskowitz, S. (1996). Immunology: $A$ short course. New York: Wiley-Liss.

Benson, H. (1993). The relaxation response. In D. Goleman \& J. Gurin (Eds.), Mind-body medicine (pp. 151-172). New York: Consumer Reports Books.

**Black, S. (1963a). Inhibition of immediate-type hypersensitivity response by direct suggestion under hypnosis. British Medical Journal, 6 , 925-929. [Excluded-Nonexperimental design]

**Black, S. (1963b). Shift in dose-response curve of Prausnitz-Kustner reaction by direct suggestion under hypnosis. British Medical Joumal, 6 , 990-992. [Excluded-Nonexperimental design]
**Black, S., \& Friedman, M. (1965). Adrenal function and the inhibition of allergic responses under bypnosis. British Medical Journal, 1, 562-567. [Excluded-Nonexperimental design]

**Black, S., Humphrey, J. H., \& Niven, J. S. (1963). Inhibition of the Mantoux reaction by direct suggestion under hypnosis. British Medical Joumal, 1, 1649-1652. [Excluded-Nonexperimental design]]

Blalock, J. E. (1994). The syntax of neuroendocrine-immune communication. Immunology Today, 15, 504-511.

Bock, K. A., \& Sabin, N. (1997). The road to immunity. New York: Pocket Books.

*Bongartz, W., Lyncker, I., \& Kossman, K. T. (1987). The influence of hypnosis on white blood cell count and urinary levels of catecholamines and vanillyl mandelic acid. Hypnos, 14, 52-61. [Relaxation intervention]

*Booth, R. J., Petrie, K. J., \& Brook, R. J. (1995). Conditioning allergic skin responses in humans: A controlled trial. Psychosomatic Medicine, 57, 492-495. [Conditioning intervention]

*Booth, R. J., Petrie, K. J., \& Pennebaker, J. W. (1996). Changes in circulating lymphocyte numbers following emotional disclosure: Evidence of buffering? Stress Medicine, 43, 293-306. [Disclosure intervention]

*Bradley, L. A., Turner, R. A., Young, L. D., Agudelo, C. A., Anderson, K. O., \& McDaniel, L. K. (1985). Effects of cognitive-behavioral therapy on pain behavior of rheumatoid arthritis patients: Preliminary outcomes. Scandinavian Joumal of Behaviour Therapy, 14, 51-64. [Stressmanagement intervention]

*Buske-Kirschbaum, A., Kirschbaum, C., Stierle, H., Jabaij, L., \& Hellhammer, D. (1994). Conditioned manipulation of natural killer (NK) cells in humans using a discriminative learning protocol. Biological Psychology, 38, 143-155. [Conditioning intervention]

*Buske-Kirschbaum, A., Kirschbaum, C., Stierle, H., Lehnert, H., \& Hellhammer, D. H. (1992). Conditioned increase of natural killer cell activity (NKCA) in humans. Psychosomatic Medicine, 54, 123-132. [Condition-
ing intervention]

**Castés, M., Hagel, I., Palenque, M., Canelones, P., Corao, A., \& Lynch, N. R. (1999). Immunological changes associated with clinical improvement of asthmatic children subjected to psychosocial intervention. Brain, Behavior, and Immunity, 13, 1-13. [Excluded-Nonexperimental design]

Cawley, R. H. (1983). The principles of treatment and therapeutic evaluation. In M. Shepherd \& O. L. Zangwill (Eds.), Handbook of psychiatry 1: General psychopathology: (pp. 221-243). Cambridge, UK: Cambridge
University Press.

**Chapman, G. F., Goodell, H., \& Wolff, H. G. (1959). Augmentation of the inflammatory reaction by activity of the central nervous system. Archives of Neurology, 1, 557-571. [Excluded-Insufficient data]

*Christensen, A. J., Edwards, D. L., Wiebe, J. S., Benotsch, E. G., McKelvey, L., Andrews, M., \& Lubaroff, D. M. (1996). Effect of verbal self-disclosure on natural killer cell activity: Moderating influence of cynical hostility. Psychosomatic Medicine, 58, 150-155. [Disclosure intervention]

**Clarkson, A. K. (1937). The nervous factor in juvenile asthma. British Medical Joumal, 1, 845-850. [Excluded--Single-subject design]

*Coates, T. J., McKusick, L., Kuno, R., \& Stites, D. P. (1989). Stress reduction training changed number of sexual partners but not immune function in men with HIV. American Joumal of Public Health, 79, 885-887. [Stress-management intervention]

Cohen, J., \& Cohen, P. (1983). Applied multiple regression/correlation for the behavioral sciences. Hillsdale, NJ: Erlbaum.

Cohen, S., Doyle, W. J., \& Skoner, D. P. (1999). Psychological stress, cytokine production, and severity of upper respiratory illness. Psychosomatic Medicine, 61, 175-180.

Cohen, S., \& Herbert, T. B. (1996). Health psychology: Psychological 
factors and physical disease from the perspective of human psychoneuroimmunology. Annual Review of Psychology, 47, 113-142.

Cohen, S., Kessler, R. C., \& Underwood, L. G. (1995). Measuring stress: A guide for health and social scientists. New York: Oxford University Press

Cohen, S., Miller, G. E., \& Rabin, B. S. (in press). Psychological stress and antibody response to antigenic challenge: A critical review. Psychosomatic Medicine.

Cohen, S., \& Williamson, G. M. (1991). Stress and infectious disease in humans. Psychological Bulletin, 109, 5-24.

*Dennis, M., \& Philippus, M. J. (1965). Hypnotic and non-hypnotic suggestion and skin response in atopic patients. American Joumal of Clinical Hypnosis, 7, 342-345. [HWIS intervention]

Dhabar, F. S., \& McEwen, B. S. (1997). Acute stress enhances while chronic stress suppresses cell-mediated immunity in vivo: A potential role for leukocyte trafficking. Brain, Behavior, and Immunity, 11, 286306.

*Ellers, L. S. (1995). Effects of two cognitive-behavioral interventions on immunity and symptoms in persons with HIV. Annals of Behavioral Medicine, 17, 339-348. [Relaxation intervention]

Epstein, G. (1989). Healing visualizations: Creating health through imag. ery. New York: Bantam Books.

*Esterling, B. A., Antoni, M. H., Fletcher, M. A., Margulies, S., \& Schneiderman, N. (1994). Emotional disclosure through writing or speaking modulates latent Epstein-Barr virus antibody titres. Joumal of Consulting and Clinical Psychology, 62, 130-140. [Disclosure intervention]

**Esterling, B. A., Antoni, M. H., Kumar, M., \& Schneiderman, N. (1990). Emotional repression, stress disclosure responses, and Epstein-Barr viral capsid antigen titers. Psychosomatic Medicine, 52, 397-410. [Excluded-Nonexperimental design]

*Esterling, B. A., Antoni, M. H., Schneiderman, N., Carver, C. S., LaPerriere, A., Ironson, G., Klimas, N. G., \& Fletcher, M. A. (1992). Psychosocial modulation of antibody to Epstein-Barr viral capsid antigen and human herpesvirus type-6 in HIV-1 infected and at-risk gay men. Psychosomatic Medicine, 54, 354-371. [Stress-management intervention]

Fawzy, F. I., Cousins, N., Fawzy, N. W., Kemeny, M. E., Elashoff, R., \& Morton, D. (1990). A structured psychiatric intervention for cancer patients: Changes over time in methods of coping and affective disturbance. Archives of General Psychiatry, 47, 720-725.

Fawzy, F. I., \& Fawzy, N. W. (1994). Psychoeducational interventions and health outcomes. In R. Glaser \& J. K. Kiecolt-Glaser (Eds.), Handbook of human stress and immunity (pp. 365-402). New York: Academic Press.

Fawzy, F. I., Fawzy, N. W., Hyun, C. S., Elashoff, R., Guthrie, D., Fahey, J. L., \& Morton, D. (1993). Malignant melanoma: Effects of an early structured psychiatric intervention, coping, and affective state on recurrence and survival 6 years later. Archives of General Psychiatry, 50, 681-689.

*Fawzy, F. I., Kemeny, M. E., Fawzy, N. W., Elashoff, R., Morton, D., Cousins, N., \& Fahey, J. L. (1990). A structured psychiatric intervention for cancer patients: Changes over time in immunological measures. Archives of General Psychiatry, 47, 729-735. [Stress-management intervention]

Felten, S. Y., \& Felten, D. (1994). Neural-immune interaction. Progress in Brain Research, 100, 157-162.

*Fry, L., Mason, A. A., \& Pearson, R. S. B. (1964). Effect of hypnosis on allergic skin responses in asthma and hay-fever. British Medical Jour. nal, 1, 1145-1148. [HWIS intervention]

Glaser, R., Kiecolt-Glaser, J. K., Marucha, P. T., MacCallum, R. C., Laskowski, B. F., \& Malarkey, W. B. (1999). Stress-related changes in pro-inflammatory cytokine production in wounds. Archives of General Psychiatry, 56, 450-456.

*Goodkin, K., Feaster, D. J., Asthana, D., Blaney, N. T., Kumar, M.,
Baldewicz, T., Tuttle, R. S., Maher, K. G., Baum, M. K., Shapshak, P. \& Fletcher, M. A. (1998). A bereavement support group intervention is longitudinally associated with salutary effects on the CD 4 cell count and number of physician visits. Clinical and Diagnostic Laboratory Immunology, 5, 382-390. [Stress-management intervention]

*Green, M. L., Green, R. G., \& Santoro, W. (1988). Daily relaxation modifies serum and salivary immunoglobulin and psychophysiologic symptom severity. Biofeedback and Self-Regulation, 13, 187-199. [Relaxation intervention]

*Green, R. G., \& Green M. L. (1987). Relaxation increases salivary immunoglobulin A. Psychological Reports, 61, 623-629. [Relaxation intervention]

*Gregerson, M. B., Roberts, I. M., \& Amiri, M. M. (1996). Absorption and imagery locate immune responses in the body. Biofeedback and SelfRegulation, 21, 149-165. [Relaxation and HWIS interventions]

**Gruber, B. L., Hall, N. R. S., Hersh, S. P., \& Dubois, P. (1988). Immune system and psychological changes in metastatic cancer patients using relaxation and guided imagery: A pilot study. Scandinavian Journal of Behaviour Therapy, 17, 25-46. [Excluded-Nonexperimental design]

*Gruber, B. L., Hersh, S. P., Hall, N. R. S., Waletzky, L. R., Kunz, J. F., Carpenter, J. K., Kverno, K. S., \& Weiss, S. M. (1993). Immunological responses of breast cancer patients to behavioral interventions. Biofeedback and Self-Regulation, 18, 1-22. [Relaxation intervention]

**Hall, H. R., Minnes, L., \& Olness, K. (1993). The psychophysiology of voluntary immunomodulation. International Journal of Neuroscience, 69, 221-234. [Excluded-Duplicate data]

*Hall, H. R., Minnes, L., Tosi, M., \& Olness, K. (1992). Voluntary modulation of neutrophil adhesiveness using a cyberphysiologic strategy. International Joumal of Neuroscience, 63, 287-297. [HWIS intervention]

**Hall, H. R., Mumma, G. H., Longo, S., \& Dixon, R. (1992). Voluntary immunomodulation: A pilot study. Intemational Journal of Neuroscience, 63, 275-285. [Excluded-Nonexperimental design]

*Hall, H. R., Papas, A., Tosi, M., \& Olness, K. (1996). Directional changes in neutrophil adherence following passive resting versus active imagery. Intemational Joumal of Neuroscience, 85, 185-194. [HWIS intervention]

Hall, N. R. S., \& O'Grady, M. P. (1991). Psychosocial interventions and immune function. In R. Ader, D. Felten, \& N. Cohen (Eds.), Psychoneuroimmunology (pp. 1067-1080). New York: Academic Press.

Halley, F. M. (1991). Self-regulation of the immune system through biobehavioral strategies. Biofeedback and Self-Regulation, 16, 55-74.

Herbert, T. B., \& Cohen, S. (1993). Stress and immunity in humans: A meta-analytic review. Psychosomatic Medicine, 55, 364-379.

*Hewson-Bower, B., \& Drummond, P. D. (1996). Secretory immunoglobulin $A$ increases during relaxation in children with and without recurrent respiratory tract infections. Journal of Developmental and Behavioral Pediatrics, 17, 311-316. [Relaxation and HWIS interventions]

Hoffman, J. W., Benson, H., Ams, P. A., Stainbrook, G. L., Landsberg, L., Young, J. B., \& Gill, A. (1982). Reduced sympathetic nervous system responsivity associated with the relaxation response. Science, 54, 190192.

**Houldin, A. H., McCorkle, R., \& Lowery, B. (1993). Relaxation training and psychoimmunological status of bereaved spouses: A pilot study. Cancer Nursing, 16, 47-52. [Excluded-Nonexperimental design]

Hoyle, R. H., \& Smith, G. T. (1994). Formulating clinical research hypotheses as structural equation models: A conceptual review. Joumal of Consulting and Clinical Psychology, 62, 429-440.

**Ikemi, Y., \& Nakagawa, S. (1962). A psychosomatic study of contagious dermatitis. Kyushu Journal of Medical Science, 13, 335-350. [Excluded-Insufficient data]

Ironson, G., Wynings, C., Schneiderman, N., Baum, A., Rodriguez, M. S., Greenwood, D., Benight, C., Antoni, M. H., LaPerriere, A., Huang. H. Klimas, N. G., \& Fletcher, M. A. (1997). Posttraumatic stress symptoms, 
intrusive thoughts, loss, and immune function after Hurricane Andrew. Psychosomatic Medicine, 59, 128-141.

Irwin, M. R., Daniels, M., Smith, T., Bloom, E. T., \& Weiner, H. (1987). Impaired natural killer cell activity during bereavement. Brain, Behavior, and Immunity, I, 98-104.

*Jasnoski, M. L., \& Kugler, J. (1987). Relaxation, imagery, and neuroimmunomodulation. Annals of the New York Academy of Science, 496, 722-730. [Relaxation intervention]

*Johnson, V. C., Walker, L. G., Heys, S. D., Whiting, P. H., \& Eremin, O. (1996). Can relaxation training and hypnotherapy modify the immune response to stress, and is hypnotizability relevant? Contemporary Hypnosis, 13, 100-108. [Relaxation intervention]

**Kaneko, Z., \& Takaishi, N. (1963). Psychosomatic studies on chronic uricaria. Folia Psychiatrica et Neurologica, 17, 17-24. [ExcludedNonexperimental design]

Kemeny, M. E., \& Miller, G. E. (1999). Effects of psychosocial interventions on immune functions. In M. Schedlowski \& U. Tewes (Eds.), Psychoneuroimmunology: A textbook (pp. 373-415). New York: Ple-
num Press.

Kemeny, M. E., Solomon, G. F., Morley, J. E., \& Herbert, T. B. (1992). Psychoneuroimmunology. In C. B. Nemeroff (Eds.), Neuroendocrinol. ogy (pp. 563-591). Boca Raton, FL: CRC Press.

**Keppel, W. H., Regan, D. H., Heffeneider, S. H., McCoy, S., \& Ramsey, F. (1993). Effects of behavioral stimulation on plasma interleukin-1 activity in humans at rest. Journal of Clinical Psychology, 49, 777-789. [Excluded-Nonexperimental design]

Kiecolt-Glaser, J. K., Dura, J. R., Speicher, C. E., Trask, O. J., \& Glaser, R. (1991). Spousal caregivers of dementia victims: Longitudinal changes in immunity and health. Psychosomatic Medicine, 53, 345-362.

Kiecolt-Glaser, J. K., Fisher, L. D., Ogrocki, P., Stout, J. C., Speicher, C. E., \& Glaser, R. (1987). Marital quality, marital disruption, and immune function. Psychosomatic Medicine, 49, 13-34.

Kiecolt-Glaser, J. K., \& Glaser, R. (1988). Methodological issues in behavioral immunology research with humans. Brain, Behavior, and Immuniry, 2, 67-78.

Kiecolt-Glaser, J. K., \& Glaser, R. (1992). Psychoneuroimmunology: Can psychological interventions modulate immunity? Journal of Consulting and Clinical Psychology, 60, 569-575.

Kiecolt-Glaser, J. K., \& Glaser, R. (1995). Measurement of immune response. In S. Cohen, R. C. Kessler, \& L. G. Underwood (Eds.), Measuring stress: A guide for health and social scientists (pp. 213-230). New York: Oxford University Press.

*Kiecolt-Glaser, J. K., Glaser, R., Strain, E. C., Stout, J. C., Tarr, K. L., Holliday, J. E., \& Speicher, C. E. (1986). Modulation of cellular immunity in medical students. Journal of Behavioral Medicine, 9, 5-21. [Relaxation intervention]

*Kiecolt-Glaser, J. K, Glaser, R., Williger, D., Stout, J. C., Messick, G., Sheppard, S., Ricker, D., Romisher, S. C., Briner, W., Bonnel, G., \& Donnerberg, R. (1985). Psychosocial enhancement of immunocompetence in a geriatric population. Health Psychology, 4, 25-41. [Relaxation intervention]

Kiecolt-Glaser, J. K., Kennedy, S., Malkoff, S., Fisher, L., Speicher, C. E., \& Glaser, R. (1988). Marital discord and immunity in males. Psychosomatic Medicine, 50, 213-229.

Kiecolt-Glaser, J. K., Marucha, P. T., Malarkey, W. B., Mercado, A. M., \& Glaser, R. (1995). Slowing of wound healing by psychological stress. Lancet, 346, 1194-1196.

*Kirschbaum, C., Jabaaij, L., Buske-Kirschbaum, A., Hennig, J., Blom, M., Dorst, K., Bauch, J., DiPauli, R., Schmitz, R., Ballieux, R., \& Hellhammer, D. H. (1992). Conditioning of drig-induced immunomodulation in human volunteers: A European collaborative study. British Joumal of Clinical Psychology, 31, 459-472. [Conditioning intervention]

Laidlaw, T. M., Booth, R. J., \& Large, R. G. (1994). The variability of type 1 hypersensitivity reactions: The importance of mood. Joumal of Psychosomatic Research, 38, 51-61.

**Laidlaw, T. M., Booth. R. J., \& Large, R. G. (1996). Reduction in skin reactions to histamine after a hypnotic procedure. Psychosomatic Medicine, 58, 242-248. [Excluded-Nonexperimental design]

*Laidlaw, T. M., Richardson, D. H., Booth, R. J., \& Large, R. G. (1994). Immediate-type hypersensitivity reactions and hypnosis: Problems in methodology. Journal of Psychosomatic Research, 38, 569-580. [HWIS intervention]

Lazarus, R. S., \& Folkman, S. (1984). Stress, appraisal, and coping. New York: Springer.

Lehrer, P. M., \& Woolfolk, R. L. (1993). Principles and practice of stress management. New York: Guilford Press.

**Lekander, M., Furst, C. J., Rotstein, S., Hursti, T. J., \& Fredrikson, M. (1997). Immune effects of relaxation during chemotherapy for ovarian cancer. Psychotherapy \& Psychosomatics, 66, 185-191. [ExcludedNonexperimental design]

Lepore, S. J., Silver, R. C., Wortman, C. B., \& Wayment, H. A. (1996). Social constraints, intrusive thoughts, and depressive symptoms among bereaved mothers. Joumal of Personality and Social Psychology, 70 271-282.

Levine, B. H. (1991). Your body believes every word you say: The language of the body/mind interaction. Fairfield, CT: Asian Publishing.

*Levine, M. I., Geer, J. H., \& Kost, P. F. (1966). Hypnotic suggestion and the histamine wheal. Allergy, 37, 246-250. [HWIS intervention]

Lieberman, D. A. (1990). Leaming: Behavior and cognition. Belmont, CA: Wadsworth.

*Locke, S. E., Ransil, B. J., Covino, N. A., Toczydlowski, J., Lohse, C. M., Dvorak, H. F., Anndt, K. A., \& Frankel, F. H. (1987). Failure of hypnotic suggestion to alter immune response to delayed-type hypersensitivity antigens. Annals of the New York Academy of Science, 496, 745-749. [HWIS intervention]

*Locke, S. E., Ransil, B. J., Zachariae, R., Molay, F., Tollins, K., Covino, N. A., \& Danforth, D. (1994). Effect of hypnotic suggestion on the delayed-type hypersensitivity response. Journal of the American Medical Association, 272, 47-52. [HWIS intervention]

Luster, A. D. (1998). Chemokines-chemotactic cytokines that mediate inflammation. New England Joumal of Medicine, 338, 436-445.

*Lutgendorf, S. K., Antoni, M. H., Ironson, G., Klimas, N. G., Kumar, M., Starr, K., McCabe, P., Cleven, K., Fletcher, M. A., \& Schneiderman, N. (1997). Cognitive-behavioral stress management decreases dysphoric mood and herpes simplex virus-type 2 antibody titres in symptomatic HIV-seropositive gay men. Joumal of Consulting and Clinical Psychology, 65, 31-43. [Stress-management intervention]

*Lutgendorf, S. K., Antoni, M. H., Kumar, M., \& Schneiderman, N. (1994). Changes in cognitive coping strategies predict EBV-antibody titre change following a stress disclosure induction. Joumal of Psychosomatic Research, 38, 63-78. [Disclosure intervention]

Marucha, P. T., Kiecolt-Glaser, J. K., \& Favagehi, M. (1998). Mucosal wound healing is impaired by examination stress. Psychosomatic Medicine, 60, 362-365.

**Mason, A. A., \& Black, S. (1958). Allergic skin responses abolished under treatment of asthma and hayfever by hypnosis. Lancet, 1, 877879. [Excluded-Single-subject design]

**McCain, N. L., Zeller, J. M., Cella, D., Urbanski, P. A., \& Novak, R. M. (1996). The influence of stress management training in HIV disease. Nursing Research, 45, 246-253. [Excluded-Nonexperimental design] McGrady, A., Conran, P., Dickey, D., Garman, D., Farris, E., \& Schumann-Brzezinski, C. (1987). Effect of biofeedback-assisted relaxation on blood pressure and cortisol levels in normotensives and hypertensives. Joumal of Behavioral Medicine, 10, 301-310.

*McGrady, A., Conran, P., Dickey, D., Garman, D., Farris, E., \& Schumann-Brzezinski, C. (1992). The effects of biofeedback-assisted relaxation on cell-mediated immunity, cortisol, and white blood cell 
count in healthy adult subjects. Joumal of Behavioral Medicine, 15, 343-354. [Relaxation intervention]

McKinnon, W., Weisse, C. S., Reynolds, C. P., Bowles, C. A., \& Baum, A. (1989). Chronic stress, leukocyte subpopulations, and humoral response to latent viruses. Health Psychology, 8, 389-402.

Mendall, M. A., Patel, P., Asante, M., Ballam, L., Morris, J., Strachan, D. P., Camm, A. J., \& Northfield, T. C. (1997). Relation of serum cytokine concentrations to cardiovascular risk factors and coronary heart disease. Heart. 78, 273-277.

Miller, G. E., Cohen, S., \& Herbert, T. B. (1999). Pathways linking major depression and immunity in ambulatory female patients. Psychosomatic Medicine, 61, 850-860.

Miller, N. E. (1969). Learning of visceral and glandular responses. Science, 163, 434-445.

*Mulder, C. L., Antoni, M. H., Emmelkamp, P. M. G., Veugelers, P. J., van de Vijver, F. A. J. R., \& de Vries, M. J. (1995). Psychosocial group intervention and the rate of decline of immunological parameters in asymptomatic HIV-infected homosexual men. Psychotherapy \& Psy. chosomatics, 63, 185-192. [Stress-management intervention]

**Nicholas, P. K., \& Webster, A. (1996). A behavioral medicine intervention in persons with HIV. Clinical Nursing Research, 5, 391-406. [Excluded-Nonexperimental design]

O'Leary, A. (1990). Stress, emotion, and human immune function. Psychological Bulletin, 108, 363-382.

*O'Leary, A., Shoor, S., Lorig, K., \& Holman, H. R. (1988). A cognitivebehavioral treatment for rheumatoid arthritis. Health Psychology, 7. 527-544. [Stress-management intervention]

Olness, K., \& Ader, R. (1992). Conditioning as an adjunct in the pharmacotherapy of lupus erythematosus. Journal of Developmental and Behavioral Pediatrics, 13, 124-125.

*Olness, K., Culbert, T., \& Uden, D. (1989). Self-regulation of salivary immunoglobulin A by children. Pediatrics, 83, 66-71. [HWIS intervention]

*Peavey, B. S., Lawlis, G. F., \& Goven, A. (1985). Biofeedback-assisted relaxation: Effects on phagocytic capacity. Biofeedback and Self-Regulation, 10, 33-47. [Relaxation intervention]

Pennebaker, J. W. (1995). Emotion, disclosure, and health. Washington, DC: American Psychological Association.

Pennebaker, J. W., \& Beale, S. K. (1986). Confronting a traumatic event: Toward an understanding of inhibition and disease. Joumal of Abnormal Psychology, 95, 274-281.

*Pennebaker, J. W., Kiecolt-Glaser, J. K., \& Glaser, R. (1988). Disclosures of traumas and immune function: Health implications for psychotherapy. Journal of Consulting and Clinical Psychology, 56, 239-245. [Disclosure intervention]

*Petrie, K. J., Booth, R. J., Pennebaker, J. W., Davison, K. P., \& Thomas, M. G. (1995). Disclosure of trauma and immune response to a Hepatitis B vaccination program. Joumal of Consulting and Clinical Psychology, 63, 787-792. [Disclosure intervention]

Rabin, B. S. (1999). Stress, immune function, and health: The connection. New York: John Wiley \& Sons.

*Richardson, M. A., Post-White, J., Grimm, E. A., Moye, L. A., Singletary, S. A., \& Justice, B. (1997). Coping, life attitudes, and immune responses to imagery and group support after breast cancer treatment. Alternative Therapies, 3, 62-70. [Relaxation intervention]

*Rider, M. S., \& Achterberg, J. (1989). Effect of music-assisted imagery on neutrophils and lymphocytes. Biofeedback and Self-Regulation, 14, 247-257. [HWIS intervention]

*Rider, M. S., Achterberg, J., Lawlis, G. F., Goven, A., Toldeo, R., \& Butler, J. R. (1990). Effect of immune system imagery on secretory IgA. Biofeedback and Self-Regulation, 15, 317-333. [Relaxation intervention]

Rosenthal, R. (1991). Meta-analytic procedures for social research. Newbury Park, CA: Sage Publications.
Rosenthal, R. (1994). Parametric measures of effect size. In H. Cooper is L. V. Hedges (Eds.), The handbook of research synthesis (pp. 231-24: New York: Russell Sage Foundation.

*Ruzyla-Smith, P., Barabasz, A., Barabasz, M., \& Warner, D. (1995: Effect of hypnosis on the immune response: B-cells, T-cells, helper ard suppressor cells. American Joumal of Clinical Hypnosis, 38, 71-79. [HWIS intervention]

**Schedlowski, M., Jung, C., Schimanski, G., Tewes, U., \& Schmoll, H. J. (1994). Effects of behavioral intervention on plasma cortisol and lymphocytes in breast cancer patients: An exploratory study. Psycho-Orcology, 3, 181-187. [Excluded-Nonexperimental design]

Schleifer, S. J., Eckholdt, H. M., Cohen, J., \& Keller, S. E. (1993). Analysis of partial variance as a statistical approach to control day to day variatica in immune assays. Brain, Behavior, and lmmunity, 7, 243-252.

Schleifer, S. J., Keller, S. E., Camerino, M., Thornton, J. C., \& Stein, M. (1983). Suppression of lymphocyte stimulation following bereavemest. Journal of the American Medical Association, 250, 374-377.

Segerstrom, S. C., Taylor, S. E., Kemeny, M. E., \& Fahey, J. L. (1993). Optimism is associated with mood, coping, and immune change in response to stress. Journal of Personality and Social Psychology, it, $1646-1655$.

Shadish, W. R., \& Haddock, C. K. (1994). Combining estimates of effect size. In H. Cooper \& L. V. Hedges (Eds.), The handbook of researis: synthesis (pp. 261-281). New York: Russell Sage Foundation.

*Smith, G. R., Conger, C., O'Rourke, D. F., Steele, R. W., Charlton, R. K. \& Smith, S. S. (1992). Psychological modulation of the delayed-tyre hypersensitivity skin test. Psychosomatics, 33, 444-451. [HWIS intervention]

*Smith, G. R., \& McDaniel, S. M. (1983). Psychologically mediated effect on the delayed hypersensitivity reaction to tuberculin in humans. $P_{5 ;-}$ chosomatic Medicine, 45, 65-70. [Conditioning intervention]

**Smith, G. R., McKenzie, J. M., Marmer, D. J., \& Steele, R. W. (1985). Psychologic modulation of the human immune response to varicella zoster. Archives of Internal Medicine, 145, 2110-2112. [ExcludedSingle-subject design]

Smyth, J. (1998). Written emotional expression: Effects sizes, outcome types, and moderating variables. Joumal of Consulting and Cliniral Psychology, 66, 164-174.

Solomon, G. F., Segerstrom, S. C., Grohr, P., Kemeny, M. E., \& Fabey, J. L. (1997). Shaking up immunity: Psychological and immunologic changes after a natural disaster. Psychosomatic Medicine, 59, 114-127.

Stockhurst, U., Gritzmann, K. K., Schottenfeld-Naor, Y., Hübinger, A., Berresheim, H. W., Steingriber, H. J., \& Gries, F. A. (1999). Classical conditioning of insulin effects in healthy humans. Psychosomatic Medicine, 61, 424-435.

Stone, A. A. (1992). Selected methodological concepts: Mediation and moderation, individual differences, aggregation strategies, and variability of replicates. In N. Schneiderman, P. McCabe, \& A. Baurn (Eds.), Stress and disease processes: Perspectives in behavioral medicine (Fo. 55-71). Hillsdale, NJ: Erlbaum.

Stone, A. A., Cox, D. S., Valolimarsdottir, H., \& Neale, J. M. (1987). Secretory IgA as a measure of immunocompetence. Joumal of Hum:an Stress. 13, 136-140.

*Taylor, D. N. (1995). Effects of a behavioral stress-management program on anxiety, mood, self-esteem, and T-cell count in HIV positive men. Psychological Reports, 76, 451-457. [Relaxation intervention]

Taylor, S. E. (1983). Adjustment to threatening events: A theory of cognitive adaptation. American Psychologist, 38, 1161-1173.

Taylor, S. E., \& Brown, J. D. (1988). Mlusion and well-being: A social psychological perspective on mental health. Psychological Bulletin, 103, 193-210

*van der Pompe, G., Duivenvoorden, H. J., Antoni, M. H., Visser, A., \& Heijnen, C. J. (1997). Effect of a short-term group psychotherapy program on endocrine and immune function in breast cancer patients: AD 
exploratory study. Joumal of Psychosomatic Research, 42, 453-466. [Stress-management intervention]

Van Rood, Y. R., Bogaards, M., Goulmy, E., \& Waletzky, L. R. (1993). The effects of stress and relaxation on the in vitro immune response in man: A meta-analytic study. Joumal of Behavioral Medicine, 16, 163179.

**West, J. R, Kierland, R., \& Litin, E. (1961). Atopic dermatitis and hypnosis: Physiologic stigmata before, during, and after hypnosis. $A r$ chives of Dermatology, 84, 95-104. [Excluded-Nonexperimental de-
sign]

Whitacre, C. C., Reingold, S. C., \& O'Looney, P. A. (1999). A gender gap in autoimmunity. Science, 283, 1277-1278.

*Whitehouse, W. G., Dinges, D. F., Orne, E. C., Keller, S. E., Bates, B. L. Bauer, N. K., Morahan, P., Haupt, B. A., Carlin, M. M., Bloom, P. B. Zaugg, L., \& Orne, M. T. (1996). Psychosocial and immune effects of self-hypnosis for stress management throughout the first semester of medical school. Psychosomatic Medicine, 58, 249-263. [Relaxation intervention]

**Wiedenfeld, S. A., O'Leary, A., Bandura, A., Brown, S., Levine, S., \& Raska, K. (1990). Impact of perceived self-efficacy in coping with stressors on components of the immune system. Joumal of Personality and Social Psychology, 59, 1082-1094. [Excluded-Nonexperimental design]

Wright, R. J., Rodriquez, M. S., \& Cohen, S. (1998). Review of psychosocial stress and asthma: An integrated biopsychosocial approach. Thorax, 53, 1066-1074.

*Zachariae, R., \& Bjerring, P. (1990). The effect of hypnotically induced analgesia on flare reaction of the cutaneous histamine prick test. $A r$.

chives of Dermatological Research, 282, 539-543. [HWIS intervention]
*Zachariae, R., \& Bjerring. P. (1993) Increase and decrease of delayed cutaneous reactions obtained by hypnotic suggestions during sensitization. Allergy, 48, 6-11. [HWIS intervention]

*Zachariae, R., Bjerring, P., \& Arendt-Nielsen, L. (1989). Modulation of Type 1 immediate and Type IV delayed immunoreactivity using direct suggestion and guided imagery during hypnosis. Allergy, 44, 537-542. [HWIS intervention]

*Zachariae, R., Hansen, J. B., Andersen, M., Jinquan, T., Petersen, K. S. S., Simonsen, C., Zachariae, C., \& Thestrup-Pedersen, K. (1994). Changes in cellular immune function after immune specific guided imagery and relaxation in high and low hypnotizable healthy subjects. Psychotherapy and Psychosomatics, 61, 74-92. [Relaxation and HWIS interventions]

*Zachariae, R., Jorgensen, M. M., Christensen, S., \& Bjerring, P. (1997). Effects of relaxation on the delayed-type hypersensitivity (DTH) reaction to diphenylcyclopropenone (DCP). Allergy, 52, 760-764. [Relaxation intervention]

**Zachariae, R., Kristensen, J. S., Hokland, P., Ellegaard, J., Metze, E., \& Hokland, M. (1990). Effect of psychological intervention in the form of relaxation and guided imagery on cellular immune function in normal healthy subjects. Psychotherapy \& Psychosomatics, 54, 32-39. [Excluded-Nonexperimental design]

*Zachariae, R., Oster, H., \& Bjerring, P. (1994). Effects of hypnotic suggestions on ultraviolet $B$ radiation-induced erythema and skin blood flow. Photodermatology, Photoimmunology, and Photomedicine, 10, 154-160. [HWIS intervention]

Zakowski, S., Hall, M. H., \& Baum, A. (1992). Stress, stress-management, and the immune system. Applied and Preventive Psychology, 1, 1-13.

**Zeller, M. (1944). The influence of hypnosis on passive transfer and skin tests. Annals of Allergy, 2, 515-517. [Excluded-Nonexperimental de-
sign] 